de la contabilidad de las obras del Puerto de La Luz y Las Palmas

(Canarias,España) a través del estudio realizado por su director el

ingeniero Juan de León y Castillo, siglos XIX y XX

\title{
ANÁLISIS DESCRIPTIVO DE LA CONTABILIDAD DE LAS OBRAS DEL PUERTO DE LA LUZ Y LAS PALMAS (CANARIAS, ESPAÑA) A TRAVÉS DEL ESTUDIO REALIZADO POR SU DIRECTOR EL INGENIERO JUAN DE LEÓN Y CASTILLO, SIGLOS XIX Y XX ${ }^{1}$
}

\author{
ACCOUNTING OF THE BUILDING WORKS OF THE PORT OF LA \\ LUZ Y LAS PALMAS (CANARY ISLANDS, SPAIN) ANALYZED \\ THROUGH THE STUDY OF ITS DIRECTOR THE ENGINEER JUAN \\ DE LEÓN Y CASTILLO, $19^{\mathrm{TH}}$ AND $20^{\mathrm{TH}}$ CENTURIES
}

\author{
Candelaria Castro Pérez \\ Mercedes Calvo Cruz
}

\begin{abstract}
RESUMEN
La construcción del Puerto de La Luz y Las Palmas, 1883-1903, fue adjudicada a la empresa inglesa Swanston and Company y dirigida por el ingeniero Juan de León y Castillo. El objetivo del presente trabajo es realizar una labor de reconstrucción, análisis e interpretación de las principales cuentas utilizadas para registrar las obras de construcción del citado puerto, el balance de las obras y el cálculo de las utilidades, todo ello a partir de los informes, cartas y demás documentos elaborados por el ingeniero Juan de León y Castillo, de acuerdo con la información que al respecto recibió de la empresa contratista y que forman parte del fondo documental Ingeniero D. Juan de León y Castillo.

Además, pondremos de manifiesto la extraordinaria labor efectuada por Juan de León y Castillo al analizar aspectos administrativos y contables que no eran de su competencia, pero tuvo la necesidad de realizar debido a los perjuicios económicos que le estaban ocasionando, como consecuencia del vínculo contractual existente con la Swanston and Company.

Por tanto, con este trabajo quisiéramos dar a conocer una faceta desconocida de este hombre ilustre y polifacético, que no se dedicó exclusivamente a la estricta labor de desarrollar aquellos conocimientos propios de la ingeniería sino que denota la curiosidad propia de un investigador y la ecuanimidad en su proceder, tal y como
\end{abstract}

\footnotetext{
${ }^{1}$ Este trabajo forma parte de un proyecto de investigación financiado por el Cabildo de Gran Canaria.
}

DE COMPUTIS Revista Española de Historia de la Contabilidad Spanish Journal of Accounting History 
se pone de manifiesto en sus reflexiones y análisis sobre la administración y la contabilidad. También con el estudio que realizó Juan de León y Castillo podremos mostrar y analizar aspectos contables de una empresa privada, Swanston and Company, relacionados con las obras de construcción del Puerto de La Luz y Las Palmas.

\section{ABSTRACT}

The construction of the Puerto de La Luz y Las Palmas, 1883-1903, was awarded to the English enterprise Swanston and Company and it was directed by the engineer Juan de León y Castillo. The aim of this paper is to make the reconstruction, analysis and interpretation of the main accounts, the balance sheet and the calculation of the returns regarding the works of building of the mentioned port. This task will be carried out on the basis of the reports, letters and other documents elaborated by the engineer Juan de León y Castillo, according to the instructions received from the contractor company. All these sources are included in the Ingeniero D. Juan de León y Castillo documentary fund.

In addition, we disclose the extraordinary labour effected by Juan de León y Castillo, who analyzed administrative and accounting issues out of his proper duties, but that he needed to do it in order to avoid the economic damages caused to him by his the contract with the Swanston and Company.

The paper reveals hence an unknown facet of this illustrious and versatile man. He did not devote himself exclusively to the strict labour of developing his knowledge of the engineering. On the contrary, he felt the characteristic curiosity of researchers and showed a great equanimity in his behaviour. His reflections and analysis on administration and accounting matters clearly manifests it. These reflections and analysis let us know and analyze moreover interesting aspects of the accounting kept by a private firm, Swanston and Company, with regard to the building works of the Puerto de La Luz y Las Palmas.

PALABRAS CLAVES:

Historia, Contabilidad, Puertos, Siglos XIX-XX

KEY WORDS:

History, Accounting, Ports, $19^{\text {th }}$ and $20^{\text {th }}$ centuries

\section{Introducción}

La construcción del Puerto de La Luz y Las Palmas, supuso para la ciudad de Las Palmas de Gran Canaria un motor impulso de su economía, que unido a los avances tecnológicos en la navegación dieron lugar a la revalorización de la posición geográfica de las Islas Canarias, como punto clave en las rutas marítimas, principalmente entre Europa, África y América.

Las empresas extranjeras que desarrollaron actividades en Gran Canaria fueron numerosas y diversos sus países de procedencia, destacando las grandes inversiones de capital inglés. La relación canario-anglosajona encuentra su punto álgido en los siglos XIX y XX, periodo en el que Canarias constituye para las compañías navieras inglesas una parada obligada en sus diversas rutas, no sólo por motivos económicos sino también por sus buenas condiciones climáticas, que atrae tanto al turista viajero como al que busca beneficios para la salud.

\section{DE COMPUTIS Revista Española de Historia de la Contabilidad} Spanish Journal of Accounting History 
de la contabilidad de las obras del Puerto de La Luz y Las Palmas

(Canarias,España) a través del estudio realizado por su director el

ingeniero Juan de León y Castillo, siglos XIX y XX

La Swanston and Company fue una de las sociedades inglesas que realizó sus actividades en Las Palmas de Gran Canaria, entre las que destaca la construcción del Puerto de La Luz y Las Palmas, cuya dirección corrió a cargo del ingeniero Juan de León y Castillo. La relación entre ambos originó una extensa documentación recopilada por el propio ingeniero y en la actualidad depositada en el Archivo Histórico Provincial de Las Palmas "Joaquín Blanco", formando parte del fondo documental denominado Ingeniero D. Juan de León y Castillo. En una primera fase de nuestra investigación procedimos a ordenar y clasificar dicho fondo en función de su procedencia, puesto que hubo que extraer la documentación relativa a la obra del Puerto de La Luz y Las Palmas, del resto de sus obras de ingeniería (distintas carreteras, la cárcel de Las Palmas, etc.) y de la correspondiente a la relación mantenida con su hermano el diplomático Fernando de León y Castillo.

La motivación del trabajo es abordar el análisis e interpretación de la contabilidad de la empresa Swanston and Company relativa a las obras del Puerto de La Luz y de Las Palmas a través de la documentación generada por el ingeniero como consecuencia del estudio que realiza de la citada contabilidad.

Asimismo, otra motivación es dar a conocer un aspecto inédito del ingeniero Juan de León y Castillo dado que se adentró en los registros contables para intentar demostrar los perjuicios económicos que la Swanston and Company le estaba ocasionando. En este sentido, lo que sí es conocido de Juan de León y Castillo son sus inquietudes en el ámbito político, filosófico y científico, dando lugar a diversas obras escritas. Entre ellas señalamos la de Martín del Castillo (1993) en torno al pensamiento del ingeniero y diversas biografías como las de Millares Torres (1982) y las publicadas por Hernández Gutiérrez (1995 y 2006). Otros trabajos se han centrado en sus obras de ingeniería entre los que se encuentran los divulgados por Martín del Castillo (1995, 1997, 2003a y 2003b). Además existen otras publicaciones dedicadas a su gran obra como fue el Puerto de la Luz y Las Palmas, en este sentido hemos de citar las siguientes: La Tipografía del Diario (1909), Moreno (1947), Suárez Falcón (1952), Burriel de Orueta (1974) y Hernández Gutiérrez (1991).

La fuente primaria del presente trabajo son los informes elaborados por Juan de León y Castillo relativos a la administración y gestión de su principal obra de ingeniería, la construcción del Puerto de La Luz y Las Palmas y la correspondencia mantenida con la constructora. No obstante, hemos de indicar la importante limitación que tiene dicha fuente primaria, al no disponer de la documentación original elaborada por la contratista Swanston and Company referente a la contabilidad de las obras del puerto. Por tanto, este estudio que hemos realizado se basa en los datos e interpretaciones que de la contabilidad realizó el ingeniero Juan de León y Castillo.

\section{DE COMPUTIS Revista Española de Historia de la Contabilidad} Spanish Journal of Accounting History 


\section{El ingeniero Juan de León y Castillo y Swanston and Company empresa constructora del Puerto de La Luz y Las Palmas}

\subsection{Juan de León y Castillo y el Puerto de la Luz y Las Palmas ${ }^{2}$}

El ingeniero Juan de León y Castillo nace el 2 de abril de 1834 en la ciudad de Las Palmas de Gran Canaria y a los 16 años se traslada a Madrid para realizar los estudios preparatorios y poder ngresar en la Escuela de Ingenieros de Caminos, Canales y Puertos. En 1858 concluye con gran éxito los mencionados estudios, destacando como el primero de su promoción.

En ese mismo año comienza Juan de León y Castillo el ejercicio de su vida profesional al ser nombrado Ingeniero Aspirante Primero a la Ayudantía de Obras Públicas de la Provincia de Canarias, lo cual le supone regresar a Canarias y fijar su residencia en Santa Cruz de Tenerife, bajo las órdenes del Ingeniero Jefe Francisco Clavijo y Pló. En estos momentos las infraestructuras públicas en Canarias se caracterizaban por un estado de abandono absoluto, viéndose desbordados los ingenieros ante la gran cantidad de obras que debían afrontar.

Al año siguiente, en 1859, establece su residencia en Gran Canaria y el 25 de octubre del mismo año es nombrado Ingeniero Primero. Su primer proyecto, ejecutado de forma brillante $^{3}$, es la carretera que une Las Palmas con Telde (segunda ciudad más importante en la isla). Además, se le encargan la redacción de todos los proyectos de obras públicas de Gran Canaria, Lanzarote y Fuerteventura, entre los que destaca su obra maestra el Puerto de La Luz y Las Palmas, cuyo proyecto definitivo presenta en 1881.

Para la realización de las obras del citado puerto fue necesaria la construcción de un gran dique de abrigo que el propio ingeniero, en su Memoria Orígenes del Puerto de Refugio de La Luz, indica que para ello adoptó un sistema novedoso en España, el sistema de bloques

\footnotetext{
${ }^{2}$ La prolífera figura de Juan de León y Castillo consecuencia de sus inquietudes en el ámbito político, filosófico y científico ha dado lugar a diversas obras escritas como son, entre otras: Martín del Castillo (1993); y diversas biografías entre las que destacamos la de Millares Torres (1982) y las publicadas por Hernández Gutiérrez (1995 y 2006). Asimismo, otros trabajos se han centrado en sus obras de ingeniería entre los que se encuentran los divulgados por Martín del Castillo (1995, 1997, 2003a y 2003b). Además existen otras publicaciones en torno a su gran obra como fue el Puerto de la Luz y Las Palmas, en este sentido hemos de citar las siguientes: La Tipografía del Diario (1909), Moreno (1947), Suárez Falcón (1952), Burriel de Orueta (1974) y Hernández Gutiérrez (1991).

${ }^{3}$ El citado proyecto, desde el punto de vista técnico, es calificado de modélico, sin lagunas legales, en el que los detalles constructivos, los cálculos, aparecen reflejados de forma magistral, con el celo de un principiante temeroso de las regañinas de sus superiores (Hernández Gutiérrez, 2006, p. 41).
}

DE COMPUTIS Revista Española de Historia de la Contabilidad Spanish Journal of Accounting History 
de la contabilidad de las obras del Puerto de La Luz y Las Palmas

(Canarias,España) a través del estudio realizado por su director el

ingeniero Juan de León y Castillo, siglos XIX y XX

concertados sin mortero en las juntas con paramentos verticales, sistema muy en boga entonces entre los ingenieros ingleses ${ }^{4}$.

El 3 de marzo de 1882 el Ministerio de Fomento aprueba el proyecto que contó con la distinción de ser publicado en la Revista de Obras Públicas $n^{\circ} 4$, tomo XXX del 28 de febrero de 1882 y a partir de ese momento sirvió como punto de referencia para los ingenieros, como así se indica en la citada publicación: con el objeto de que los lectores de la Revista tengan conocimiento de él y puedan, los que necesiten consultar trabajos de esta índole, tenerle en cuenta en la seguridad de que estudiándole detenidamente, obtendrán útiles y provechosos resultados prácticos.

Acompañaba al proyecto de las obras su correspondiente presupuesto, que ascendió a 8.639.675,90 pesetas, y el plazo fijado para su culminación que se determinó en ocho años. Ahora bien, el corto periodo estimado para la realización de las obras suponía una inversión anual por parte del Estado de más de 1.000 .000 pesetas y como vía para disminuir la citada inversión estatal se acordó con el ingeniero Juan de León y Castillo ampliar el plazo de ejecución de las mismas.

Dicho plazo se logra aumentar a dieciocho años al objeto, tal y como se indica en la Real Orden de 28 de febrero de 1882 que anuncia la subasta de las obras del puerto, de que cada año no sea necesario destinar á este servicio más de quinientas mil pesetas de la cantidad consignada en el presupuesto para construcción de puertos, que corren a cargo de este Ministerio.

La primera subasta de las obras del puerto quedó desierta debido, principalmente, a su largo plazo de ejecución que implicaba mantener durante 18 años una fianza del $10 \%$ del remate. Ante esta situación Juan de León y Castillo se traslada a Madrid para intentar resolver los obstáculos y consigue rebajar el deposito a la mitad pero manteniéndose el plazo de realización de las obras.

El 28 de septiembre de 1882 tiene lugar la segunda subasta, adjudicándose las obras a una empresa londinense muy conocida en Las Palmas Swanston and Company y al Sr. Juan Bautista Ripoche comerciante de esta ciudad.

La empresa contratista, Swanston and Company, se caracterizó por su capacidad y solvencia económica, rasgos que contribuyeron a que las obras del puerto se ejecutaran de forma regular, sin paralizaciones ni demoras. Además, como señala Quintana Navarro (1985, p.33) la empresa aprovechó la contrata para obtener ventajas comerciales y pingues ganancias al amparo de las obras que realizaba.

La construcción del Puerto de La Luz y Las Palmas supuso la primera gran obra de ingeniería en las Islas Canarias y trajo consigo importantes medios tecnológicos como fueron

\footnotetext{
4 Archivo Histórico Provincial de Las Palmas (AHPLP), Fondo documental Juan de León y Castillo (18521916), registro 233.
}

\section{DE COMPUTIS Revista Española de Historia de la Contabilidad} Spanish Journal of Accounting History 
la maquinaria de vapor, necesaria para la elaboración de morteros y hormigones, la gran explanada para la construcción de los bloques y todos los elementos imprescindibles para la cimentación y construcción de los diques, sin olvidar la gran grúa Titán que era vital para elevar y conducir los bloques a su emplazamiento definitivo.

El 5 de septiembre de 1903 se produce la entrega de las obras al Gobierno español, cuyo importe final de la liquidación se incrementó en casi 400.000 pesetas con respecto a la cantidad rematada por la Swanston and Company, debido a la existencia de partidas no presupuestadas inicialmente y a los problemas surgido por la conducción de las aguas.

\subsection{Las compañías extranjeras en Canarias: Swanston and Company ${ }^{5}$}

A lo largo de los siglos ha sido muy notable la presencia de compañías extranjeras en las Islas Canarias -inglesas, irlandesas, holandesas, ente otras- las cuales se afincaban atraídas en un principio por el comercio de exportación de la caña de azúcar y más adelante por los estimados vinos canarios, constituyendo la producción de malvasía el principal atractivo para la llegada del capital inglés. No obstante, en el siglo XVIII entra en crisis el mercado vinícola y ocasiona el abandono de las islas por parte de numerosa población inglesa.

Hacia la segunda mitad del siglo XVIII y como consecuencia de los enfrentamientos entre católicos y protestantes en Inglaterra, se produce una nueva afluencia a las islas de expatriados irlandeses que encuentran en la población canaria, católica por excelencia, una cálida acogida.

Ahora bien, la relación canario-anglosajona encuentra su punto álgido en los siglos XIX y XX, periodo en el que Canarias, por su estratégica situación, constituye para las compañías navieras inglesas una parada obligada en sus diversas rutas -continente africano, Nueva Zelanda, etc.-, unido a la fama adquirida por sus buenas condiciones climáticas que atrae no sólo al turista viajero sino también al que busca beneficios para la salud. Todo ello ocasionó la necesidad de construir un gran puerto, el Puerto de La Luz y de Las Palmas, y el consiguiente desarrollo económico, social y cultural de la capital de Gran Canaria.

Entre los extranjeros que recibe Canarias destacamos la llegada fortuita del primer Swanston, el escocés Diego Swanston Miller, que se dirigía a las Antillas, lugar donde se encontraba establecida gran parte de la familia Swanston con evidentes signos de prosperidad económica, pero las inevitables corrientes del Golfo desviaron su embarcación hacia las Islas Canarias, circunstancia que fue aprovechada por los piratas para saquearle y abandonarle en la isla de Fuerteventura junto al resto de desafortunados pasajeros.

\footnotetext{
5 Para un mejor conocimiento de las compañías extranjeras que desarrollaron actividades comerciales en Canarias en la época objeto de estudio pueden consultarse las siguientes obras, entre otras, Herrera Piqué (1977), Martín Hernández (1995), Morales Lezcano (1971) y Rodríguez Díaz de Quintana (1989).
}

DE COMPUTIS Revista Española de Historia de la Contabilidad Spanish Journal of Accounting History 
de la contabilidad de las obras del Puerto de La Luz y Las Palmas

(Canarias,España) a través del estudio realizado por su director el ingeniero Juan de León y Castillo, siglos XIX y XX

El joven Diego Swanston Miller, cuando sólo contaba con 14 años, se traslada en 1812 a la capital grancanaria y contacta con Francisco Gourié, empresario francés que comenzaba a destacar en la ciudad por sus notables dotes mercantiles, quien le convierte en su protegido y le introduce en el mundo de los negocios.

El 26 de junio 1831, Diego Swanston junto con su hermano Jorge y su primo Tomás Miller funda una sociedad colectiva denominada Swanston y Compañía por un año que luego se prorrogaría seis años más (véase esquema 1). Tal y como señala Rodríguez Díaz de Quintana (1989, p. 72) la duración máxima de este tipo de operaciones mercantiles era de seis años, ahora bien si tal vínculo mercantil resultaba provechoso se suscribían posteriores prórrogas con una duración de ocho e incluso diez años.

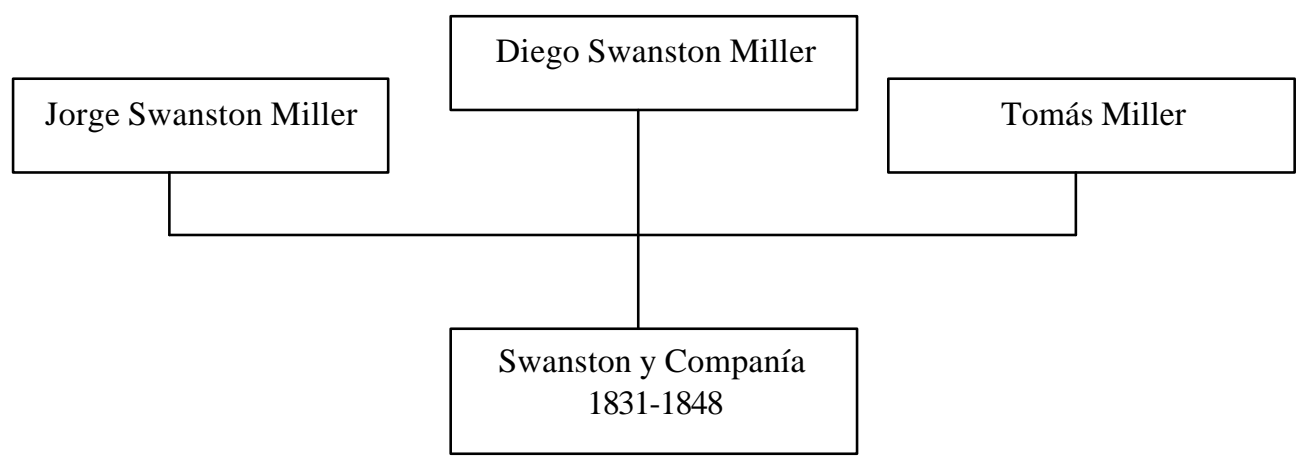

Esquema 1: Miembros fundadores de la Swanston y Compañía

La citada sociedad colectiva Swanston y Compañía prestó concreta atención a la empresa marítima y a los servicios portuarios de suministro [...] fueron, además, exportadores de cochinilla, la cual vendían a Francia, desde donde se enviaba a China (Herrera Piqué, 1977, p. 7).

Como consecuencia de la decisión de Diego Swanston Miller de regresar a su patria, se disuelve en 1848 la empresa Swanston y Compañía. Años más tarde, uno de sus hijos, Juan Swanston, en unión de un familiar, José Miller Vasconcellos hijo de Tomás Miller, fundan la sociedad Swanston and Company de Londres. Esta sociedad, tal y como se ha indicado anteriormente, será la que remate en pública subasta la adjudicación de las obras de construcción del Puerto de La Luz y Las Palmas.

DE COMPUTIS Revista Española de Historia de la Contabilidad Spanish Journal of Accounting History 
de la contabilidad de las obras del Puerto de La Luz y Las Palmas

(Canarias,España) a través del estudio realizado por su director el ingeniero Juan de León y Castillo, siglos XIX y XX

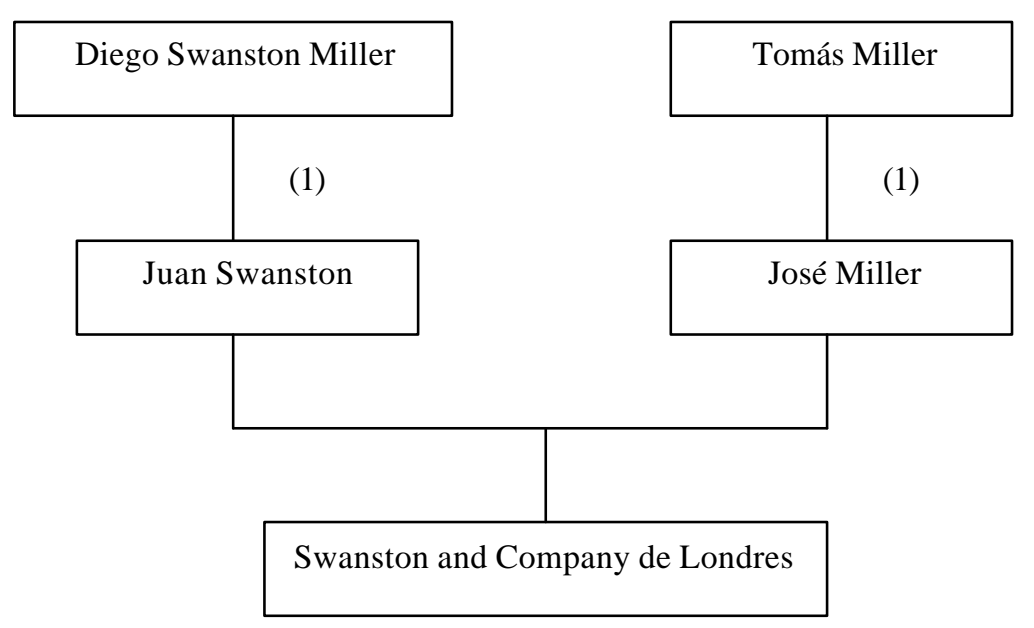

(1) Hijos de Diego y Tomás, respectivamente.

Esquema 2: Miembros fundadores de la Swanston and Company de Londres

\subsection{Relación contractual entre Juan de León y Castillo y la Swanston and Company}

En abril de 1891, estando Juan de León y Castillo en Londres, los señores Juan Swanston y José Miller Vasconcellos, representantes de la empresa contratistas de las obras del Puerto de La Luz y Las Palmas, le proponen la dirección facultativa de las mismas, ofrecimiento que acepta bajo las condiciones detalladas en el contrato privado firmado por la Swanston and Company en Londres el 24 de julio de 1891 y por Juan de León y Castillo el 23 de octubre de ese mismo año.

El citado contrato ${ }^{6}$ consta de diez cláusulas que versan sobre los siguientes temas: la persona de Juan de León y Castillo y el compromiso adquirido; remuneración; y aspectos administrativos y contables. Del análisis de los artículos primero, segundo y séptimo se observa cómo Juan de León y Castillo no sólo fue requerido por sus conocimientos técnicos, como Ingeniero Director y Consultivo en las Obras del Puerto, sino también por sus conocidas influencias, tanto en Canarias como en Madrid, en lo social y en lo político.

Los aspectos relativos a la remuneración que recibiría Juan de León y Castillo son ampliamente tratados en el contrato, dedicándole cinco cláusulas y una adición. Finalmente, a los aspectos administrativos y contables se les dedica los dos últimos artículos, donde la Swanston and Company fue contundente al dejar claramente especificado que no se crearía

\footnotetext{
${ }^{6}$ Para un mejor seguimiento de este trabajo se ha trascrito el contrato en el Anexo 1.

DE COMPUTIS Revista Española de Historia de la Contabilidad Spanish Journal of Accounting History
} 
una sociedad mercantil entre las partes contratantes, decisión que implicaba la no intervención de Juan de León y Castillo en la administración y en la contabilidad de las obras del puerto, negándosele incluso la posibilidad de exigir cuentas.

No obstante, hemos de señalar que a la recepción del contrato por Juan de León y Castillo para su firma, observa que en el mismo no están recogidas algunas cuestiones tratadas previamente entre ellos y que conformaron las bases previas. Esta circunstancia le llevó a manifestar su desacuerdo con determinadas cláusulas del contrato, realizando una exhaustiva comparación entre las citadas bases y el contrato, al djeto de dar a conocer a la compañía contratista los perjuicios que le iban a ocasionar y proponer algunas soluciones ${ }^{7}$.

Ante esta situación, Juan de León y Castillo requiere información económicofinanciera a la Swanston and Company, la cual le es denegada por ajustarse la compañía inglesa a la cláusula décima del contrato que le prohibía el acceso a la información contable. Ahora bien, un hecho circunstancial como es el fallecimiento del Sr. Forman, representante de la Swanston and Company en Las Palmas, ocasiona que sea la propia constructora quien le solicita al ingeniero que se encargue de la administración de las obras, es en este momento, 1 de julio de 1896, cuando accede a la documentación contable y se propicia el poder revisarla y analizarla.

En el siguiente apartado, una vez descritas las prácticas contables seguidas por la Swanston and Company en las obras de construcción del Puerto de La Luz y Las Palmas, procederemos a realizar una labor de reconstrucción, análisis e interpretación de las principales cuentas utilizadas para registrar las obras del citado puerto, a partir de los informes, cartas y demás documentos elaborados por Juan de León y Castillo, de acuerdo con la información que al respecto recibió el ingeniero de la empresa contratista.

\section{La contabilidad de las obras del Puerto de La Luz y Las Palmas}

Antes de comenzar este apartado destacamos una vez más que la limitación de no disponer de la documentación original elaborada por la contratista Swanston and Company, referente a la contabilidad de las obras del puerto, propiciará que el desarrollo del mismo se base en los datos e interpretaciones que de la contabilidad realizó el ingeniero Juan de León y Castillo.

\subsection{Las prácticas contables de la Swanston and Company}

Juan de León y Castillo en una carta-borrador ${ }^{8}$ dirigida a la compañía Swanston, con fecha 16 de noviembre de 1898, con motivo de una reclamación por estar disconforme con las cantidades que le habían abonado, realiza una breve descripción de las prácticas contables

\footnotetext{
${ }^{7}$ Estas cuestiones han sido ampliamente tratadas en Calvo, Castro y Granado (2009) y en Calvo y Castro (2010).

${ }^{8}$ AHPLP, Fondo documental Juan de León y Castillo (1852-1916), registro 20.
}

\section{DE COMPUTIS Revista Española de Historia de la Contabilidad} Spanish Journal of Accounting History 
utilizadas por la Swanston and Company para llevar los libros de contabilidad de las obras, y detalla las premisas a tener en cuenta para la elaboración de la citada información contable.

En la mencionada carta-borrador, deja constancia en primer lugar del procedimiento contable aplicado por la compañía Swanston, es decir el método de la partida doble. En este sentido, hemos comprobado en la documentación disponible la efectiva aplicación del método de la partida doble, puesto que se verifican las características básicas del mismo, como son la existencia del Libro Diario y del Libro Mayor y la consecuente doble anotación en ambos, la igualdad en el montante del crédito y del debito y la homogeneidad en la unidad monetaria utilizada.

A continuación el ingeniero señala unas bases que considera se han tenido en cuenta a la hora de elaborar los libros de contabilidad. En la primera de ellas hace referencia a la unidad monetaria a utilizar para formar las cuentas, es decir, la peseta. Ahora bien, al realizar también operaciones con casas inglesas y francesas, las monedas utilizadas serán la libra esterlina y el franco, respectivamente, indicando el tipo de cambio para su conversión en pesetas, como Juan de León y Castillo especifica en otra premisa ${ }^{9}$ :

"[...] que en los asientos del Diario y en las cuentas del Mayor, se consignan las monedas extranjeras, pero se reducen a pesetas, adoptando siempre el cambio que se denomina a la par, o sea 25 ptas. por libra esterlina y 1 por 1 franco".

En esta base se fija el tipo de cambio que debía de aplicarse y queda reflejada la utilización de los dos libros imprescindibles que conforman el método contable. Además, la existencia de libros auxiliares es detallada por el ingeniero en otro de los informes ${ }^{10}$ que elabora, al examinar los libros de contabilidad de las obras del puerto correspondientes al periodo de 1 de julio de 1891 a 1 de julio de 1901 como son: Borrador del Diario; libros auxiliares para las cuentas de arena, cal, bloques, etc. y Borrador definitivo.

En otra de las premisas muestra el doble carácter de la Swanston and Company, puesto que no sólo actuó como contratista de las obras del puerto sino que también desempeñó la labor de comisionista de las mismas al realizar diversas operaciones de intermediación, como por ejemplo entre la empresa proveedora de materiales y las obras del puerto. Sin olvidar las ganancias obtenidas como consecuencia de la fluctuación favorable de la libra esterlina en relación a la peseta.

Finalmente, en otra base Juan de León y Castillo señala que la empresa contratista de Londres contaba con una sucursal en Las Palmas, Swanston and Company de Las Palmas, que actuaban como agentes a las órdenes de Swanston and Company de Londres. Asimismo,

\footnotetext{
9 AHPLP, Fondo documental Juan de León y Castillo (1852-1916), registro 20.

${ }^{10}$ AHPLP, Fondo documental Juan de León y Castillo (1852-1916), registro 32.
}

DE COMPUTIS Revista Española de Historia de la Contabilidad Spanish Journal of Accounting History 
de la contabilidad de las obras del Puerto de La Luz y Las Palmas

(Canarias,España) a través del estudio realizado por su director el

ingeniero Juan de León y Castillo, siglos XIX y XX

expone el ingeniero las competencias a desempeñar por los agentes, como fueron: inspeccionar las obras, comprar los efectos necesarios, verificar los pagos de jornales y materiales y consignar los asientos en el libro Diario de acuerdo con lo determinado por la compañía de Londres.

También Juan de León y Castillo en el estudio de la documentación facilitada por la Swanston and Company se detiene a explicar detalladamente las funciones que debía desempeñar la persona que llevaba la contabilidad, en este caso el contable Juan Antúnez, como eran redactar el Borrador del Libro Diario y los libros auxiliares, indicando lo siguiente ${ }^{l l}$ :

"[...] de este Borrador el empleado de la Casa copia los asientos y a ellos añade las operaciones de Caja correspondientes, cambios, intereses etc. etc. y forma así el Borrador definitivo de los libros, que copiado en el Diario y pasados sus asientos al Mayor, constituyen estos dos últimos los libros legales de la contrata".

Además, al final de cada año el contable elaboraba los inventarios y en base a ellos confeccionaba el Balance general de las obras.

\subsection{Principales cuentas utilizadas por la Swanston and Company}

El estudio que Juan de León y Castillo realiza de la documentación contable comienza con el examen de las cuentas utilizadas, que a su juicio ofrecían un mayor interés, como son: Cuenta corriente de las obras con los Sres. Swanston y Cia. de Londres, Cuenta corriente de Swanston y Cia. de Las Palmas, Cuenta de utilidades y Cuenta del depósito de carbón adosado al Dique de abrigo.

\section{Cuenta corriente de las obras con los Sres. Swanston y Cia. de Londres}

El ingeniero comienza analizando la Cuenta corriente de las obras con los Sres. Swanston y Cia. de Londres y justifica la importancia de la misma en atención al artículo $6^{\circ}$ del contrato, puesto que de su saldo dependía tanto el reparto de las utilidades anuales (beneficio) que se realizaba cada 30 de junio, como la constitución de un fondo que debía dotar la compañía Swanston en Madrid, como garantía de las obras del puerto.

En la figura 1 (Anexo 2) se muestra la Cuenta corriente de las obras con los Sres. Swanston y Cia. de Londres, donde se puede apreciar la estructura de la misma, es decir, en forma de libro abierto y dedicando la parte izquierda al Debe y la derecha al Haber. Ambas partes, Debe y Haber, se disponen en cinco columnas, que de izquierda a derecha nos indican lo siguiente: año y mes, día, cuerpo del asiento en el que se explica el motivo de la anotación,

\footnotetext{
${ }^{11}$ AHPLP, Fondo documental Juan de León y Castillo (1852-1916), registro 32.
}

\section{DE COMPUTIS Revista Española de Historia de la Contabilidad} Spanish Journal of Accounting History 
cuantía de la operación en libras esterlinas y reservando la última columna para expresar este mismo importe en pesetas.

Seguidamente reconstruimos, analizamos e interpretamos los principales movimientos de la Cuenta corriente de las obras con los Sres. Swanston y Cia. de Londres, utilizando para ello las anotaciones y transcripciones que de la misma realizó Juan de León y Castillo y plasmó en diversos informes.

Entre las operaciones derivadas de la función de la Swanston and Company como contratista de las obras figuran los desembolsos que realizan por envío de maquinaria, útiles, herramientas, servicios de profesionales, etc., las cuales ocasionaban una anotación en el Haber de la cuenta, que podría reflejarse a través de la siguiente anotación:

\begin{tabular}{|c|c|c|c|}
\hline Útiles y herramientas & $\mathrm{a}$ & $\begin{array}{l}\text { C/c de las obras con los Sres. } \\
\text { Swanston y Cia. de Londres }\end{array}$ & pesetas $\mathrm{xxxxxx}$ \\
\hline
\end{tabular}

Otro motivo de abono de la Cuenta corriente de las obras con los Sres. Swanston y Cia. de Londres viene causado por la adquisición de materiales necesarios para las obras del puerto, actuando en este caso la empresa contratista como intermediaria. Sirva de ejemplo los $\operatorname{asientos}^{12}$ correspondientes a la compra y posterior pago de cemento Pórtland, cuya factura asciende a 100 libras esterlinas:

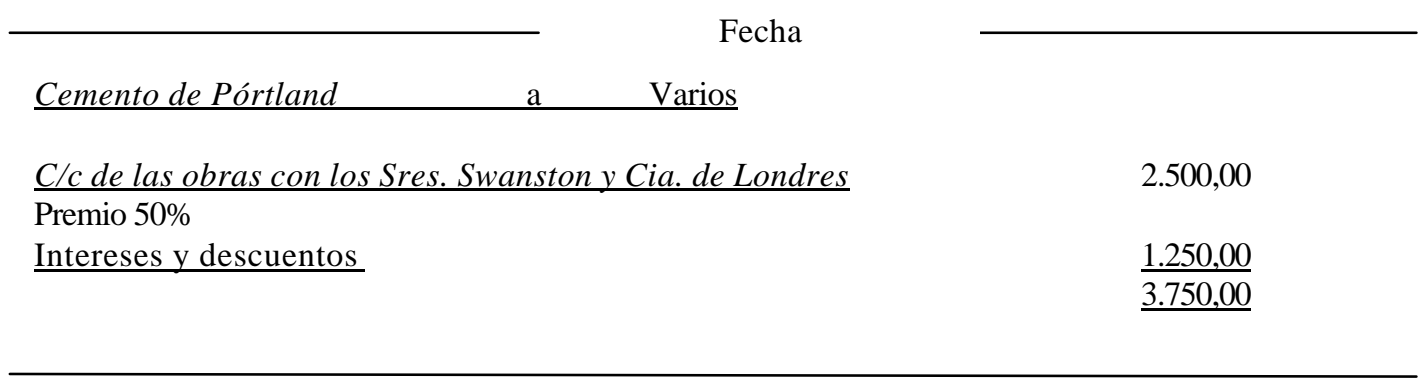

\footnotetext{
${ }^{12}$ Se observa el uso del término "Varios" para reflejar la utilización de diversas cuentas cargadas o abonadas en el mismo asiento. En algunos casos Juan de León y Castillo subraya estas cuentas (cargadas o abonadas), entendemos que para distinguir en el cuerpo del asiento la propia cuenta de la explicación que de ella solía darse.
}

\section{DE COMPUTIS Revista Española de Historia de la Contabilidad} Spanish Journal of Accounting History 
de la contabilidad de las obras del Puerto de La Luz y Las Palmas

(Canarias,España) a través del estudio realizado por su director el ingeniero Juan de León y Castillo, siglos XIX y XX

\begin{tabular}{lc}
\hline \multicolumn{1}{c}{ a } & \multicolumn{1}{c}{ Fecha } \\
\cline { 2 - 2 } Varios & \\
\hline C/c de las obras con los Sres. Swanston y Cia. de Londres & $2.500,00$ \\
Premio 60\% & $\underline{1.500,00}$ \\
$\underline{\text { Intereses y descuentos }}$ & $\underline{4.000,00}$ \\
\hline
\end{tabular}

Como puede observase en ambos asientos no sólo se refleja la compra y posterior pago de cemento Pórtland sino que también se contabiliza la diferencia existente en ese momento entre la peseta y la libra esterlina. En este sentido hemos de indicar que la relación entre ambas monedas quedó fijada de forma implícita, 1 libra esterlina igual a 25 pesetas, en una adición que se realizó al contrato firmado entre Juan de León y Castillo y la Swanston and Company, como respuesta de la contratista a la solicitud de Juan de León y Castillo de recibir unos adelantos trimestrales:

"A ruego del Sor. Don Juan de León y Castillo se ha convenido en anticiparle anualmente la suma de quince mil pesetas (15.000) o sean seiscientas libras (£ 600) a cuenta de las $£ 1.000$ que le corresponde según la cláusula 6 . Estos adelantos se harán en Las Palmas en sumas iguales de tres mil setecientas cincuenta pesetas (3.750) cada trimestre y el Sor. León y Castillo abonará un interés del 6\% anual desde la fecha de la entrega hasta el de reembolso".

Un ejemplo de la oscilación de las monedas se puede observa en el asiento correspondiente a la compra de cemento Pórtland, ya expuesto, en el que se utiliza la expresión "Premio 50\%" para reflejar que la paridad implícita en la adición había sufrido un incremento en el citado porcentaje, es decir, en esa fecha una libra esterlina equivalía a 37,50 pesetas. Es decir, Swanston and Company contabilizaba la operación al tipo de cambio vigente, pero la diferencia entre el tipo de cambio acordado en la adición al contrato y el actual lo registraba en la cuenta Intereses y descuentos. De tal forma que la operación analizada quedaba reflejada en la Cuenta corriente de las obras con los Sres. Swanston y Cia. de Londres, de la cual se extraía la información para el reparto de las utilidades, al tipo de cambio fijado en la adición al contrato. Esta manera de actuar la mantuvo la Swanston and Company en todas sus operaciones, tal y como seguiremos exponiendo.

Asimismo, otra operación vinculada con la función de contratista de la Swanston and Company registrada en la Cuenta corriente de las obras con los Sres. Swanston y Cia. de Londres era el reparto de utilidades que se efectuaba cada 30 de junio en función del saldo de

\section{DE COMPUTIS Revista Española de Historia de la Contabilidad} Spanish Journal of Accounting History 
de la contabilidad de las obras del Puerto de La Luz y Las Palmas

(Canarias,España) a través del estudio realizado por su director el ingeniero Juan de León y Castillo, siglos XIX y XX

esta cuenta (artículo $6^{\circ}$ del contrato). No obstante, en cumplimiento del contrato firmado entre el ingeniero y la Swanston and Company, y de acuerdo con la adición al mismo, Juan de León y Castillo percibía adelantos trimestrales de 150 libras esterlinas a cuenta de las citadas utilidades, de tal forma que cada 30 de junio el total de utilidades a recibir por el ingeniero no debía superar la cifra de 1.000 libras esterlinas. Estos anticipos originaban una anotación en el Debe de la citada cuenta, sirva de ejemplo el asiento realizado el 28 de diciembre de 1891:

28 de diciembre de 1891

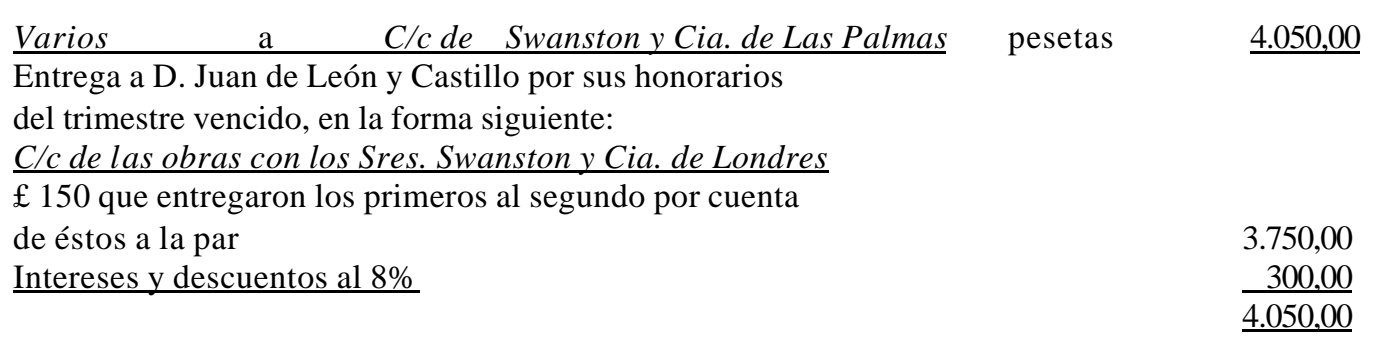

Como puede observarse en la anotación contable, al igual que en los asientos anteriores, no sólo se refleja la entrega del anticipo por la cuantía correspondiente sino que también se contabiliza la diferencia existente en ese momento entre la peseta y la libra esterlina.

Consecuentemente, cada 30 de junio, por aplicación del artículo $6^{\circ}$ del contrato se repartían en concepto de utilidades un máximo de 3.000 libras esterlinas (75.000,00 pesetas), de las que una tercera parte le correspondían a Juan de León y Castillo de acuerdo al artículo $3^{\circ}$. Ahora bien, al ingeniero se le deducían los anticipos recibidos (600 libras esterlinas) y percibía la diferencia, es decir, 400 libras esterlinas (10.000,00 pesetas), que originarían las siguientes anotaciones contables:

DE COMPUTIS Revista Española de Historia de la Contabilidad Spanish Journal of Accounting History 

de la contabilidad de las obras del Puerto de La Luz y Las Palmas (Canarias,España) a través del estudio realizado por su director el ingeniero Juan de León y Castillo, siglos XIX y XX

\section{Fecha}

C/c de las obras con los Sres. Swanston y Cia. de Londres

$a$

C/c Swanston y Cia. de Las Palmas pesetas $10.000,00$

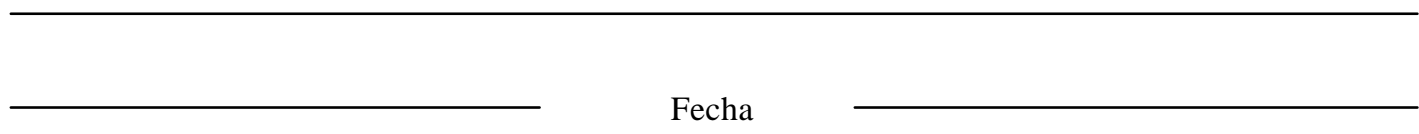

Utilidades

a

C/c de las obras con los Sres. Swanston y Cia. de Londres pesetas 75.000,00

Otro registro contable en la Cuenta corriente de las obras con los Sres. Swanston y Cia. de Londres es consecuencia de la retirada de fondos que realiza la empresa contratista al transferir a Londres las remesas sobrantes de las obras, operación que critica el ingeniero Juan de León y Castillo con las siguientes palabras ${ }^{13}$ : siempre están poniendo fondos en Londres para tenerlos en su poder. El asiento que se realizaba revestía la siguiente forma ${ }^{14}$ :

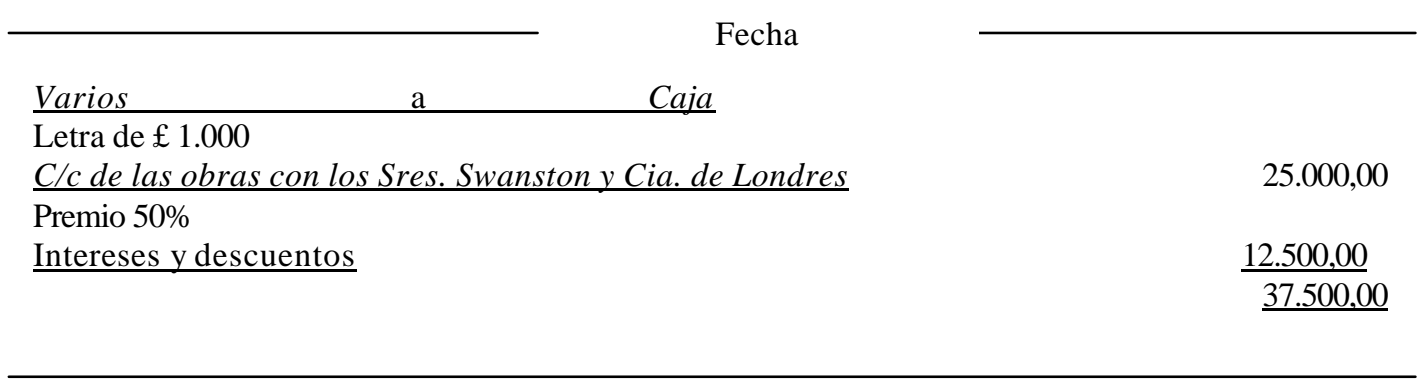

La Cuenta corriente de las obras con los Sres. Swanston y Cia. de Londres también se utiliza para registrar operaciones ajenas a las obras del puerto como son las entregas de los corresponsales de la provincia para posteriormente enviarlos a Swanston and Company de Londres, operación duramente criticada por Juan de León y Castillo en los distintos informes que emitió:

\footnotetext{
13 AHPLP, Fondo documental Juan de León y Castillo (1852-1916), registro 20.

14 AHPLP, Fondo documental Juan de León y Castillo (1852-1916), registro 20.
}

\section{DE COMPUTIS Revista Española de Historia de la Contabilidad Spanish Journal of Accounting History}


de la contabilidad de las obras del Puerto de La Luz y Las Palmas

(Canarias,España) a través del estudio realizado por su director el ingeniero Juan de León y Castillo, siglos XIX y XX

"El procedimiento es, por lo tanto defectuoso, por lo que al contrato se refiere, y además es irregular por los perjuicios evidentes que causa, nacidos de la falta de separación, que es de todo punto necesaria, entre las operaciones que se hacen por cuenta de las obras, y las que son de la exclusiva de los Sres. Swanston de Londres. Este es un principio tan elemental de contabilidad, respecto del cual no puede alegarse ignorancia". ${ }^{15}$

Un ejemplo que serviría para ilustrar esta operación, podría ser la entrega de 40 libras esterlinas que realiza el corresponsal Eloy Domínguez a la cuenta corriente de las obras del puerto para con posterioridad remesar a Londres. Al ser realizadas ambas operaciones en fechas distintas, las obras del puerto sufrirán la diferencia ocasionada por la variación en el tipo de cambio. En este caso las anotaciones contables podrían adoptar la siguiente estructura:

\section{Fecha}

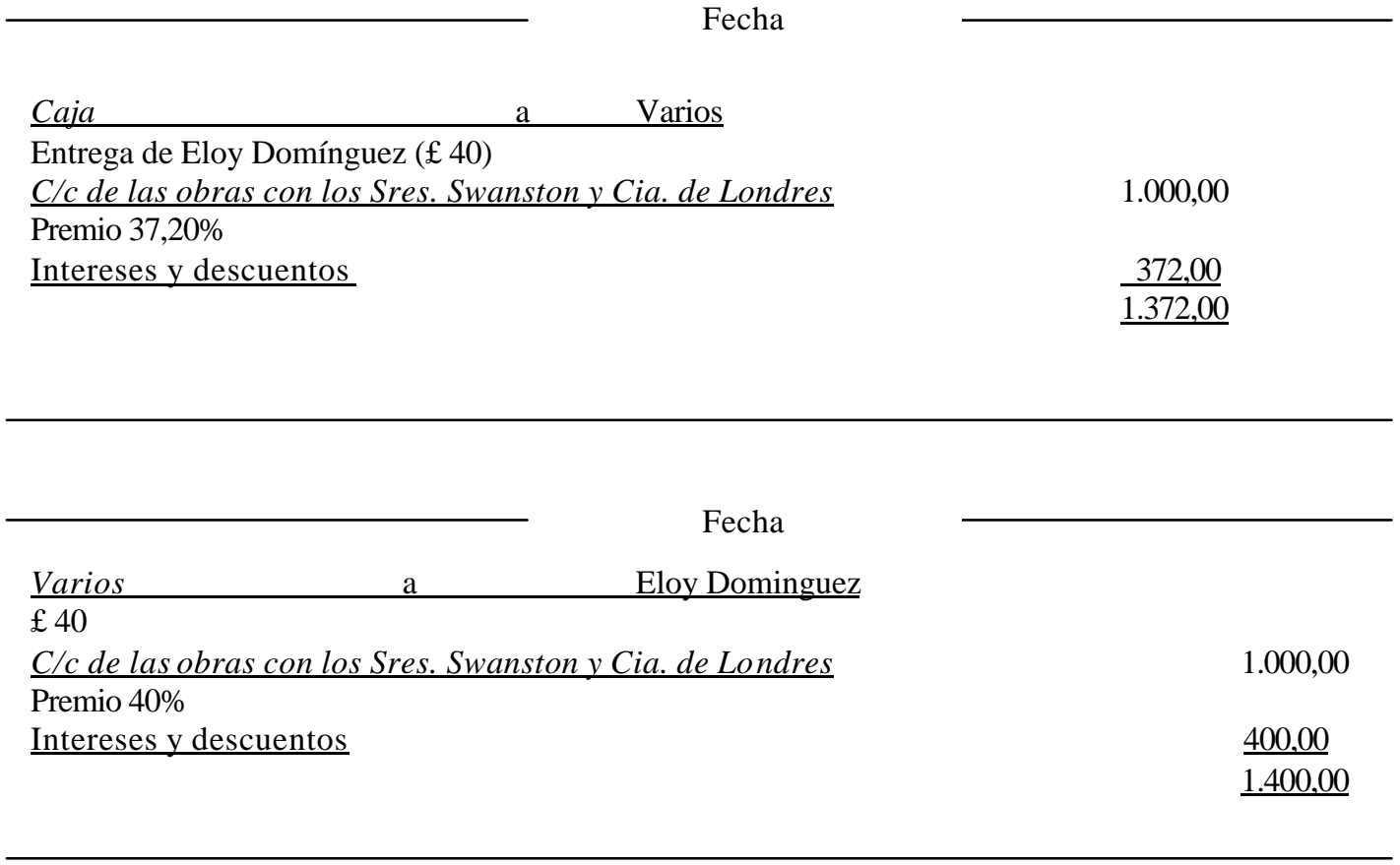

Por tanto, de acuerdo con lo señalado respecto a la utilización de la Cuenta corriente de las obras con los Sres. Swanston y Cia. de Londres podemos afirmar que en la misma se registran operaciones que podrían catalogarse en tres tipos: en atención al doble carácter

\footnotetext{
${ }^{15}$ AHPLP, Fondo documental Juan de León y Castillo (1852-1916), registro 30.

DE COMPUTIS Revista Española de Historia de la Contabilidad Spanish Journal of Accounting History
} 
de la contabilidad de las obras del Puerto de La Luz y Las Palmas

(Canarias,España) a través del estudio realizado por su director el

ingeniero Juan de León y Castillo, siglos XIX y XX

ostentado por la Swanston and Company, contratista y comisionista, y las originadas por operaciones ajenas a las obras del puerto.

Finalmente, hemos elaborado el esquema 3 con el objeto de representar, a modo de resumen, los motivos de cargo y abono de la Cuenta corriente de las obras con los Sres. Swanston y Cia. de Londres analizados anteriormente, indicando a través del subrayado los movimientos que se corresponden con actividades ajenas a las obras de construcción del puerto.

DEBE Cuenta corriente de las obras con los Sres. Swanston y Cia. de Londres HABER

* Pago de materiales

* Anticipo a Juan de León y Castillo

* Resto de utilidades para Juan de León y Castillo

* Envío de fondos sobrantes a Londres

* Envío a Londres de las entregas de

corresponsales de Provincia
* Adquisición de materiales

* Envío de maquinaria, útiles, etc.

* Total utilidades retiradas ( $£ 3.000)$

* Entrega de corresponsales de Provincia

Esquema 3: Motivos de cargo y abono de la Cuenta corriente de las obras con los Sres. Swanston y Cia. de Londres

\section{Cuenta corriente de Swanston y Cia. de Las Palmas}

La Cuenta corriente de Swanston y Cia. de Las Palmas también reviste la forma de libro abierto, dedicando la parte izquierda al Debe y la derecha al Haber. En la figura 2 (Anexo 3) se puede apreciar la división de la citada cuenta en cinco columnas, que de izquierda a derecha nos indican lo siguiente: año y mes, día, cuerpo del asiento en el que se explica el motivo de la anotación precedida en el Debe por el vocablo "a" y en el Haber por la palabra "De", desglose de la información contenida en la última columna para algunos casos y finalmente, la quinta columna detalla la cuantía en pesetas.

En general, en el Haber de la Cuenta corriente de Swanston y Cia. de Las Palmas se refleja el devengo de las distintas obligaciones de pago contraídas por Swanston and Company de Las Palmas y en el Debe se asienta el cumplimiento de las citadas atenciones. Asimismo, la cuenta recoge diferentes cargos y abonos originados por movimientos de efectivo.

Las obligaciones de pago hacen referencia principalmente a diferentes gastos propios de las obras de construcción del puerto, como son la compra de materiales (cemento, arena,

\section{DE COMPUTIS Revista Española de Historia de la Contabilidad} Spanish Journal of Accounting History

No. 13

Diciembre 2010 
útiles, etc.); los anticipos a cuenta de las utilidades que, tal y como se ha referido con anterioridad, percibe Juan de León y Castillo trimestralmente; los arrendamientos de almacenes; los gastos semestrales por la administración y los gastos facultativos de carácter trimestral que, por aplicación de la cláusula $5^{\mathrm{a}}$ del contrato, serán de la exclusiva cuenta del señor León y Castillo y se deducirán de la tercera parte de las utilidades.

A continuación, se representan en el esquema 4 los motivos de cargo y abono de la Cuenta corriente de Swanston y Cia. de Las Palmas.

\begin{tabular}{|c|c|}
\hline Cuenta corriente de Swanston & Cia. de Las Palmas \\
\hline * Pago de anticipos a Juan de León y Castillo & * Devengo del anticipo a Juan de León y Castillo \\
\hline * Alquiler de almacenes & * Devengo del alquileres de almacenes \\
\hline * Pago de materiales & * Gastos facultativos trimestrales \\
\hline \multirow[t]{3}{*}{ * Efectivo } & * Gastos de administración semestrales \\
\hline & * Honorarios \\
\hline & * Efectivo \\
\hline
\end{tabular}

Esquema 4: Motivos de cargo y abono de la Cuenta corriente de Swanston y Cia. de Las Palmas

\section{Cuenta de utilidades}

La Cuenta de utilidades se iba adeudando, año tras año, por los beneficios repartidos entre los Sres. Swanston y Juan de León y Castillo hasta el límite anual de 3.000 libras esterlinas en atención al contrato firmado entre ambos, como ya se ha señalado anteriormente.

Al érmino de las obras de construcción del puerto, el saldo de esta cuenta reviste gran importancia dado que refleja el total de beneficios repartidos y si éstos se comparan con el resultado acumulado obtenido durante el periodo de construcción de la citada infraestructura, surgía el montante final de beneficios a repartir.

\section{Cuenta del depósito de carbón adosado al Dique de abrigo}

Esta cuenta se abre para reflejar el coste de construcción de un depósito de carbón adosado al dique de abrigo del puerto que realiza la Swanston and Company. Por tanto, es un ejemplo de los privilegios con los que contó la citada empresa por ser contratista de las obras del Puerto de La Luz y Las Palmas. En diciembre de 1892 se concluye la citada obra del depósito de carbón y se salda y cierra la Cuenta del depósito de carbón adosado al Dique de abrigo.

\section{DE COMPUTIS Revista Española de Historia de la Contabilidad Spanish Journal of Accounting History}


$\mathrm{Al}$ respecto Juan de León y Castillo señala ${ }^{16}$ que, "tampoco ha debido figurar esta cuenta en la contabilidad de las obras, por tratarse de un negocio particular de los Sres. Swanston que ninguna relación tiene con aquellos; pero ya que se ha hecho así tocamos también hacer algunas observaciones acerca de ello. No la conocemos al detalle, pero nos figuramos que se habrá ido adeudando con las cantidades pagadas, materiales suministrados, etc., etc.

En la figura 3 (Anexo 4) se muestra la Cuenta del depósito de carbón adosado al Dique de abrigo, observando su división en cinco columnas de tal forma que, de izquierda a derecha, la primera se dedica a los años y meses, la siguiente indica el día del mes, a continuación figura el cuerpo principal de la cuenta y destina las dos últimas columnas al Debe y Haber de la cuenta, respectivamente.

Respecto a la columna dedicada al cuerpo principal de la cuenta, hemos de señalar su peculiar estructura puesto que se divide en dos partes con la finalidad de explicar el asiento realizado en el libro Diario. En este sentido, se dedica la parte derecha para especificar el motivo que justifica el movimiento de la citada cuenta y en la parte izquierda se detalla la contrapartida, precedida de la palabra "A" cuando se trata de un cargo en la Cuenta del depósito de carbón adosado al Dique de abrigo y para un abono se antepone el vocablo "Por". Para finalizar las observaciones en cuanto a la estructura y el contenido de esta cuenta señalar que las cantidades vienen expresadas únicamente en pesetas.

En general la Cuenta del depósito de carbón adosado al Dique de abrigo presenta saldo deudor, puesto que se carga por los costes atribuibles a la construcción del depósito como son materiales, jornales, visita mensual a las obras, etc.

A modo de reflexión, hemos de señalar que si se dispusiera de esta cuenta desde su apertura, con motivo de la construcción del depósito, hasta su cierre por finalización de la citada obra, se podría realizar un estudio no sólo del importe total de la misma sino también desglosar entre los diferentes conceptos de gastos que intervinieron en su fabricación.

No obstante, en tres ocasiones se producen anotaciones en el haber de la Cuenta del depósito de carbón adosado al Dique de abrigo para reflejar reembolsos a las obras del puerto, dado que las mismas reflejaron en su contabilidad los costes del depósito de carbón, gastos ajenos a la construcción del puerto, y también para ajustar dichos costes al tipo de cambio fijado en la adición al contrato existente entre Juan de León y Castillo y Swanston and Company.

La primera de ellas se produce en junio de 1892 al traspasar $125.000,00$ pesetas a la Cuenta corriente de las obras con los Sres. Swanston y Cia. de Londres por el coste aproximado del depósito hasta ese momento, debiendo realizarse la siguiente anotación contable:

${ }^{16}$ AHPLP, Fondo documental Juan de León y Castillo (1852-1916), registro 20.

DE COMPUTIS Revista Española de Historia de la Contabilidad Spanish Journal of Accounting History 
de la contabilidad de las obras del Puerto de La Luz y Las Palmas

(Canarias,España) a través del estudio realizado por su director el ingeniero Juan de León y Castillo, siglos XIX y XX

30 de junio de 1892
C/c de las obras con los Sres. Swanston y Cia. de Londres
C/ depósito carbón adosado Dique abrigo pesetas $125.000,00$

Obsérvese como en el asiento anterior no se tiene en cuenta la fluctuación de la moneda, y es por ello que el 30 de noviembre de 1892 para ajustar al tipo de cambio fijado implícitamente en el contrato, 1 libra esterlina equivale a 25 pesetas, se produce el siguiente asiento:

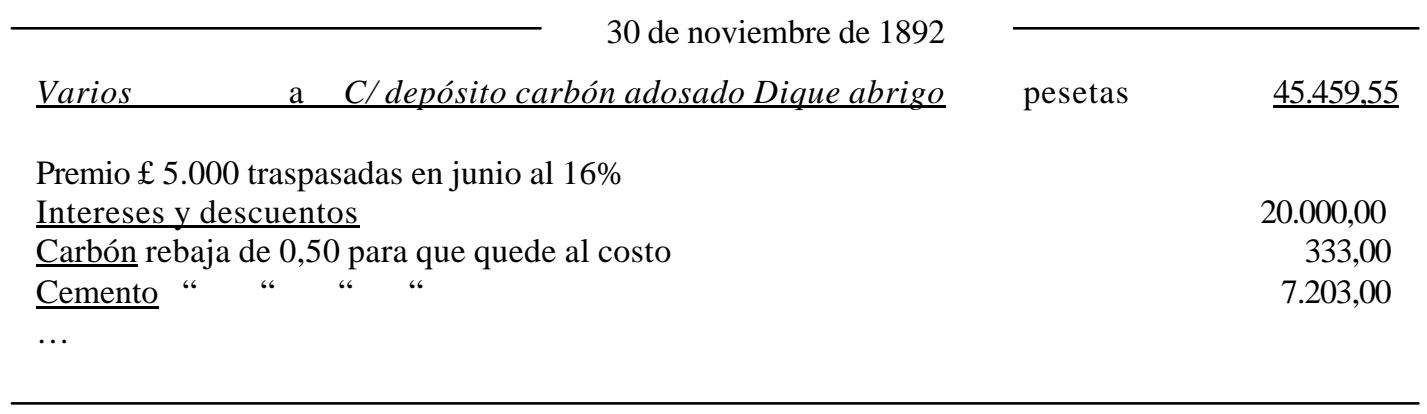

Y el último reembolso que se realiza a las obras del puerto es el 31 de diciembre de 1892, momento en el cual se salda la Cuenta del depósito de carbón adosado al Dique de abrigo mediante el siguiente asiento:

\begin{tabular}{|c|c|c|}
\hline a $C /$ depósito carbón adosado Dique abrigo & pesetas & $\underline{27.556,40}$ \\
\hline \multicolumn{3}{|l|}{ Traspaso del saldo $£ 950-4-4$ a la par } \\
\hline C/c de las obras con los Sres. Swanston y Cia. de Londres & & $23.755,40$ \\
\hline \multicolumn{3}{|l|}{ Premio al $16 \%$} \\
\hline \multirow[t]{2}{*}{$\underline{\text { Intereses y descuentos }}$} & & $3.800,84$ \\
\hline & & $\underline{56,40}$ \\
\hline
\end{tabular}

Por tanto, Juan de León y Castillo en sus informes pretendía demostrar como la edificación del depósito de carbón, obra ajena a la construcción del puerto, influyó de manera

\section{DE COMPUTIS Revista Española de Historia de la Contabilidad Spanish Journal of Accounting History}


negativa en los resultados de la contabilidad del puerto, puesto que a pesar de que los coste soportados por el citado depósito fueron reembolsados y registrado en la Cuenta corriente de las obras con los Sres. Swanston y Cia. de Londres, nuevamente la paridad de la moneda implícita en la adición del contrato supuso un coste añadido que tuvieron que soportar las obras del puerto.

A modo de resumen, se representan en el esquema 5 los motivos de cargo y abono de la Cuenta del depósito de carbón adosado al Dique de abrigo:

DEBE

Cuenta del depósito de carbón adosado al Dique de abrigo

HABER

$\begin{array}{ll}* \text { Materiales } & * \text { Costo de las obras (30-06-1892) } \\ * \text { Jornales } & * \text { Ajuste al tipo de cambio (31-11-1892) } \\ * \text { Visita mensual a la obra } & * \text { Cierre al finalizar la obra (31-12-1892) }\end{array}$

Esquema 5: Motivos de cargo y abono de la Cuenta del depósito de carbón adosado al Dique de abrigo

Una vez descritos los principales movimientos de las cuentas analizados por Juan de León y Castillo procede realizar el esquema 6 al objeto de plasmar la relación entre las citadas cuentas y de esta forma conseguir su mejor comprensión.

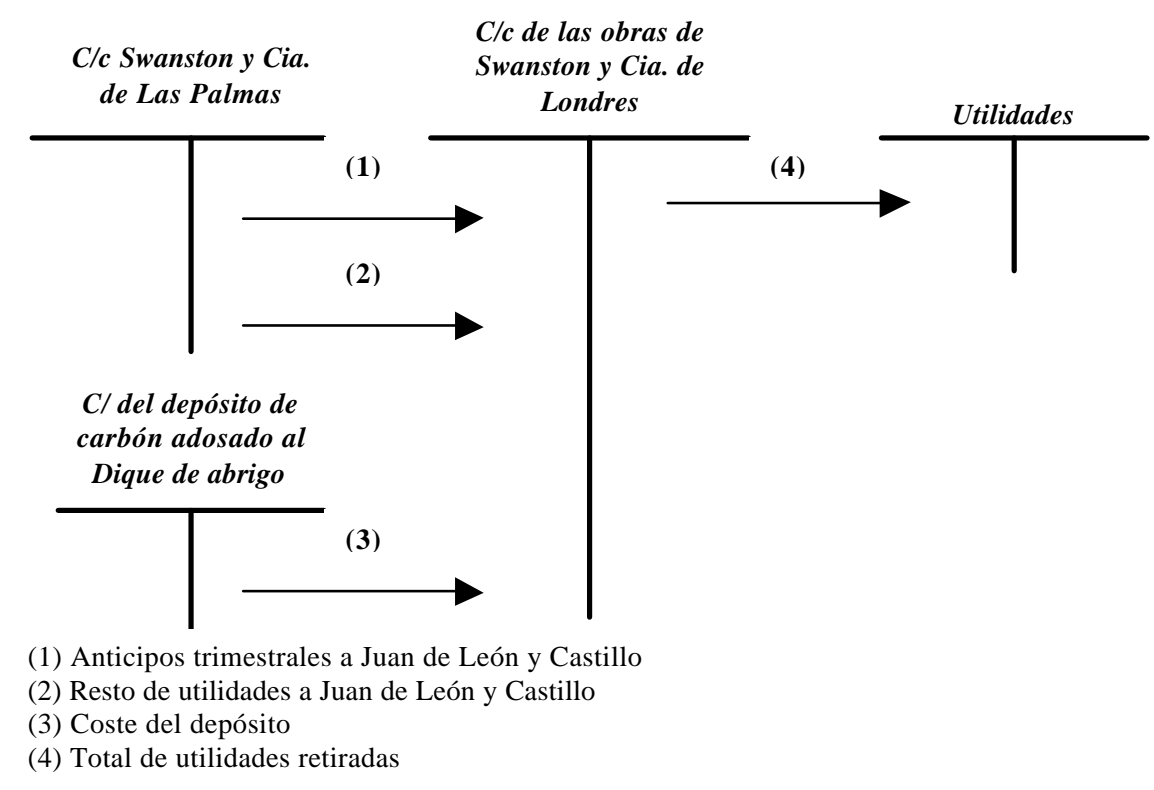

Esquema 6: Relación entre las cuentas analizadas por Juan de León y Castillo

\section{DE COMPUTIS Revista Española de Historia de la Contabilidad Spanish Journal of Accounting History}


De acuerdo con las explicaciones realizadas de las cuentas analizadas por el ingeniero y este esquema 4, se observa como la Cuenta corriente de las obras con los Sres. Swanston y Cia. de Londres es aquella que registra información de todas las demás, de ahí su importancia y relevancia para conocer las operaciones económicas llevadas a cabo por la empresa contratista, como consecuencia de la construcción del Puerto de La Luz y Las Palmas.

\subsection{Balances y cálculos de las utilidades}

En el estudio que realiza Juan de León y Castillo de la contabilidad de la Swanston and Company respecto a las obras de construcción del Puerto de La Luz y Las Palmas, no sólo se centra en el análisis de las cuentas que podrían afectarle a la hora de repartir las utilidades acordadas, sino que examina y trascribe los Balances de todas las cuentas relacionadas con las citadas obras, además de realizar toda una serie de cálculos para determinar la cuantía anual y acumulada de dichas utilidades.

\section{Balances de las cuentas de las obras del puerto}

En el fondo documental que constituye la base del presente trabajo se encuentran las trascripciones de los Balances de cuentas de las obras del Puerto, correspondientes al periodo de 30 de junio de 1895 a 30 de junio de 1901, realizadas por Juan de León y Castillo. La fecha de elaboración de tales trascripciones viene condicionada por el artículo $6^{\mathbf{0}}$ del contrato (ver anexo 1) al indicar que el reparto de las utilidades se debía realizar el 30 de junio de cada año; no obstante, en algunos ejercicios económicos también figuran Balances referidos a 31 de diciembre y 31 de marzo. Por todo ello, se observa que no existe un patrón en cuanto a la periodicidad con la que el ingeniero elabora las citadas trascripciones; ahora bien, si además figuraran las correspondientes al 31 de octubre encontraríamos su razón de ser por la aplicación de la adición al contrato, que señalaba que el ingeniero recibiría adelantos trimestrales de las utilidades anuales, lo que explicaría la confección de balances trimestrales.

En cuanto a la justificación del inicio de las trascripciones podría venir dada por el hecho de que Juan de León y Castillo, tal y como se ha indicado anteriormente, accede a la documentación contable el 1 de julio de 1896 y pudo transcribir los balances correspondientes al año anterior.

En los Balances de cuentas de las obras del Puerto, tal y como su nombre indica, se recogen todas las cuentas relacionadas con las citadas obras con indicación del saldo deudor o acreedor de acuerdo con el Libro Mayor. En este sentido, tal y como se aprecia en las figura 4 (ver Anexo 5), el Balance presenta una estructura similar a lo que en la actualidad se conoce como Balance de comprobación de saldos, toda vez que utiliza la parte izquierda para

\section{DE COMPUTIS Revista Española de Historia de la Contabilidad} Spanish Journal of Accounting History 
de la contabilidad de las obras del Puerto de La Luz y Las Palmas

(Canarias,España) a través del estudio realizado por su director el

ingeniero Juan de León y Castillo, siglos XIX y XX

referenciar la página del Mayor donde se encuentra la cuenta y el nombre de la misma ${ }^{17} \mathrm{y}$ dedicando dos columnas a la derecha para reflejar el correspondiente saldo (deudor o acreedor).

\section{Cálculo de las utilidades}

Continuando con la exposición y análisis de los estudios realizados por Juan de León y Castillo sobre la contabilidad de la compañía contratista Swanston and Company corresponde en este apartado centrarnos en el cálculo de una variable de gran importancia para el ingeniero como es la utilidad, entendida como el beneficio obtenido en el desarrollo de la actividad contratada.

En este sentido, tal y como ya se ha indicado anteriormente, la relevancia de la utilidad quedó implícita en el contrato firmado entre ambas partes, al vincular en su artículo $6^{\circ}$ el sueldo que debía percibir el ingeniero a la obtención de unas utilidades anuales mínimas. Asimismo, al finalizar las obras del puerto Juan de León y Castillo recibiría una tercera parte de las utilidades acumuladas, es decir la suma de los excedentes no repartidos en cada ejercicio económico (artículo $4^{\circ}$ ).

Por tanto, el ingeniero realiza una serie de cálculos con el objetivo de determinar y verificar tanto las utilidades anuales como las acumuladas. Para la determinación de los mismos contaba, en un principio, con las liquidaciones anuales que la Swanston and Company le entregaba, como así dejó constancia en el propio documento con las siguientes palabras $^{18}$ : estos datos fueron tomados de la liquidación que me presentó D. Juan Swanston en esta fecha”.

Esta circunstancia cambió a partir de 1 de julio de 1896, momento en el que la empresa constructora le solicita, como ya se ha señalado con anterioridad, que se haga cargo de la administración al fallecer el Sr. Forman. Por ello, a partir de esa fecha en el citado documento no figura ningún cálculo tan sólo se específica la cuantía de la liquidación anual de las utilidades, haciendo referencia al Libro Mayor donde se encuentra la información, como así lo reflejó Juan de León y Castillo ${ }^{19}$ : liquidación de 30 de junio de 1897, cuya copia integra se halla en el Libro Mayor que llevo desde 1' Julio 1896”.

Encontramos justificado el proceder del ingeniero puesto que desde que tiene acceso a la información económico-contable revisa los datos y calcula las utilidades de cada periodo económico, comenzando en 1891, fecha en la que firma el contrato con la Swanston and

\footnotetext{
${ }^{17}$ En la actualidad y por aplicación del Plan General de Contabilidad español no se hace referencia a la página del libro Mayor dado que cada cuenta tiene su propio código numérico.

18 AHPLP, Fondo documental Juan de León y Castillo (1852-1916), registro 33.

19 AHPLP, Fondo documental Juan de León y Castillo (1852-1916), registro 33.
}

DE COMPUTIS Revista Española de Historia de la Contabilidad Spanish Journal of Accounting History 
de la contabilidad de las obras del Puerto de La Luz y Las Palmas

(Canarias,España) a través del estudio realizado por su director el

ingeniero Juan de León y Castillo, siglos XIX y XX

Company, y concluyendo cuando accede a dicha administración de las obras del Puerto de La Luz y Las Palmas.

Al final del documento Juan de León y Castillo detalla la cuantía de las utilidades parciales y acumuladas. Para un mejor seguimiento hemos elaborado la tabla 1, en la cual se puede observar el único periodo económico en el que se producen utilidades negativas, es decir, desde 30 de junio de 1895 hasta 30 de junio de 1896.

\begin{tabular}{|c|c|c|}
\hline AÑO & UTILIDAD PARCIAL & UTILIDAD ACUMULADA \\
\hline 1891 & & $1.086 .818,23$ \\
\hline 1892 & $125.347,15$ & $1.212 .165,38$ \\
\hline 1893 & $115.757,42$ & $1.327 .922,80$ \\
\hline 1894 & $151.722,95$ & $1.479 .645,75$ \\
\hline 1895 & $94.963,10$ & $1.574 .608,85$ \\
\hline 1896 & $(54.376,30)$ & $1.520 .232,55$ \\
\hline 1897 & $182.464,32$ & $1.702 .696,87$ \\
\hline
\end{tabular}

Tabla 1: Cuantía de las utilidades

A continuación explicaremos las operaciones realizadas por el ingeniero para la determinación de las utilidades acumuladas, tomando como ejemplo los cálculos efectuados el 30 de junio de 1894, recogidos en la figura 5 (ver Anexo 6).

En primer lugar Juan de León y Castillo realiza el cálculo de las utilidades acumuladas obtenidas por diferencia entre el importe presupuestado hasta la fecha para las obras ejecutadas mas acopios, menos el coste de las mismas que figura desglosado en diversas partidas como son, entre otras, gastos facultativos y compras de materiales.

Asimismo, una vez calculadas las utilidades acumuladas distingue entre la parte de las mismas que ya han sido cobradas y las pendientes de cobrar. Las primeras de ellas, las utilidades cobradas, las obtiene por diferencia entre las cantidades efectivamente libradas por el Estado, recogidas en la cuenta Libramientos, y el costo de las obras. A su vez, el total de libramientos se desglosa entre libramientos recibidos, reflejados en la cuenta Banco de España, y libramientos pendientes de recibir, recogidos en la cuenta Obras Pública.

Para una mayor comprensión de la exposición realizada sobre el cálculo de las utilidades acumuladas se ha elaborado el esquema 7.

\section{DE COMPUTIS Revista Española de Historia de la Contabilidad} Spanish Journal of Accounting History 
de la contabilidad de las obras del Puerto de La Luz y Las Palmas

(Canarias,España) a través del estudio realizado por su director el ingeniero Juan de León y Castillo, siglos XIX y XX

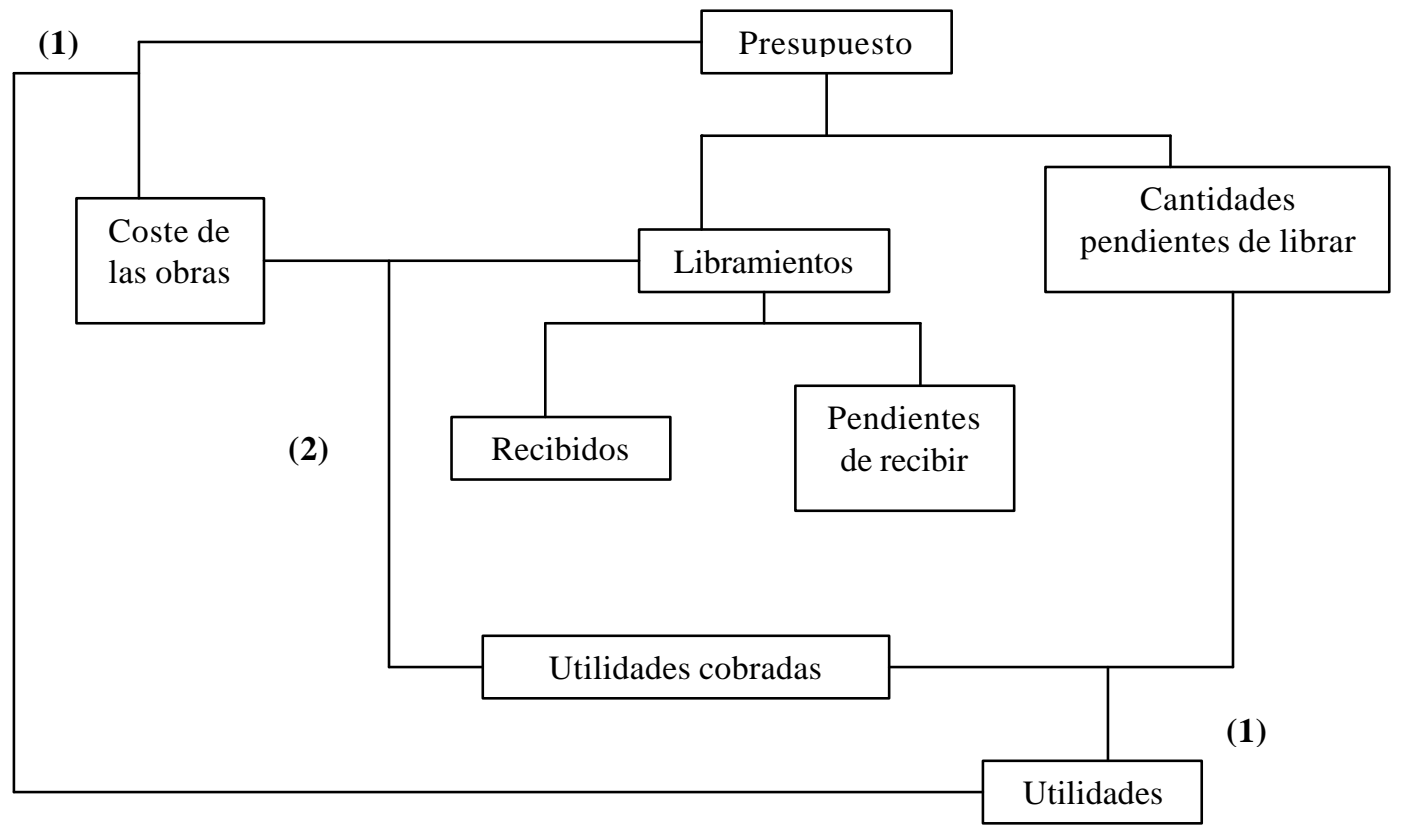

Donde:

(1) Presupuesto - Coste de las obras = Utilidades, o también

(1) Cantidades pendientes de librar + Utilidades cobradas = Utilidades

(2) Libramientos - Coste de las obras = Utilidades cobradas

Nota: todos los conceptos expresados se refieren a cuantías acumuladas

Esquema 7: Cálculo de las utilidades acumuladas

Una vez calculadas las utilidades acumuladas Juan de León y Castillo obtiene la utilidad correspondiente al periodo anual objeto de estudio, de 30 de junio de 1893 a 30 de junio de 1894, por diferencia entre las utilidades acumuladas de dos periodos consecutivos, como muestra la figura 6 (ver Anexo 7). También determina el ratio de rentabilidad de las obras mediante el cociente entre las utilidades del periodo (151.722,95 pesetas) y las cantidades asignadas al mismo (506.904,29 pesetas), que para el periodo de 30 de junio de 1893 a 30 de junio 1894 supone un $29 \%$.

No obstante, sus cálculos no finalizan con la determinación de la utilidad anual, sino que el objetivo final de los mismos era argumentar, a través de los datos obtenidos de la contabilidad, la cuantía por la que la empresa contratista de las obras se encontraba en deuda con el ingeniero. En este sentido obtiene las utilidades a repartir entre ambas partes, Juan de

\section{DE COMPUTIS Revista Española de Historia de la Contabilidad} Spanish Journal of Accounting History 
de la contabilidad de las obras del Puerto de La Luz y Las Palmas

(Canarias,España) a través del estudio realizado por su director el

ingeniero Juan de León y Castillo, siglos XIX y XX

León y Castillo y la Swanston and Company, deduciendo de las utilidades acumuladas hasta el momento 18.000 libras esterlinas, correspondientes a las utilidades que por aplicación del artículo $4^{\circ}$ del contrato, se estimaron que se habían obtenido hasta el momento de firmarlos Juan de León y Castillo y la empresa contratista.

Asimismo, por aplicación del artículo $3^{\circ}$ del citado contrato le corresponde al ingeniero una tercera parte, de la cual deduce las cantidades ya recibidas anualmente en concepto de retribución a sus labores de Ingeniero Director y Consultivo de las obras del puerto (artículo $6^{\circ}$ ) y determina la cuantía por la que en ese momento es acreedor de la compañía contratista Swanston and Company.

Concretamente, para el periodo de 30 de junio de 1893 a 30 de junio 1894 y haciendo uso de las palabras del ingeniero existencia mía en poder de Swanston ascendieron a 243.215,23 pesetas. El proceso para determinar las utilidades pendientes de recibir por Juan de León y Castillo se ha sintetizado en el esquema 8.

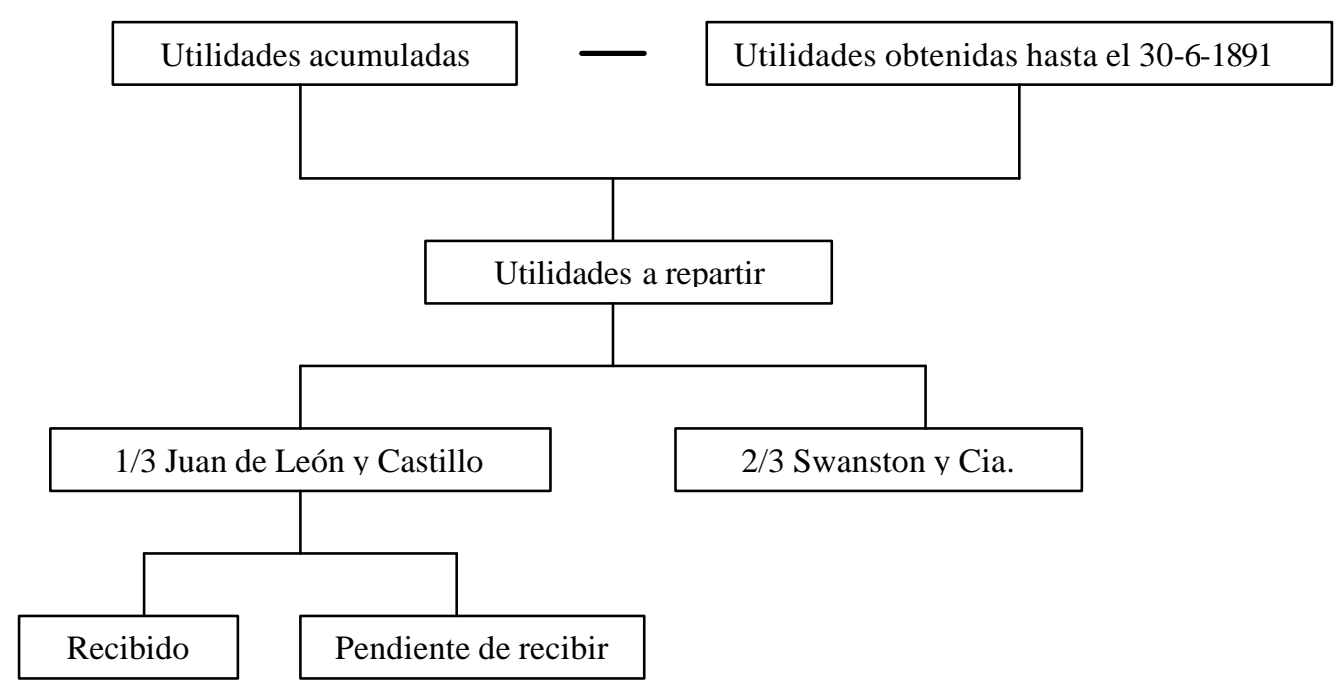

Esquema 8: Cálculo de las utilidades pendientes de recibir por Juan de León y Castillo

Del análisis realizado de la contabilidad de las obras del Puerto de La Luz y Las Palmas a través de la información unas veces transcrita y otras elaborada por Juan de León y Castillo, hemos podido constatar la amplia comprensión que el ingeniero poseía de los libros contables que debían llevarse, las características de los mismos, la técnica contable utilizada y la normativa aplicable. Gracias a estos amplios conocimientos pudo realizar el estudio y análisis de los registros contables de la empresa contratista, a partir del momento en el que tiene

\section{DE COMPUTIS Revista Española de Historia de la Contabilidad} Spanish Journal of Accounting History 
de la contabilidad de las obras del Puerto de La Luz y Las Palmas

(Canarias,España) a través del estudio realizado por su director el

ingeniero Juan de León y Castillo, siglos XIX y XX

acceso a la documentación contable, que le sirvieron para poner de manifiesto numerosas irregularidades en las operaciones económicas relativas a las obras del puerto, como consecuencia del acceso que por circunstancias de la vida tuvo a la documentación contable.

\section{Consideraciones finales}

Como consecuencia de las obras de construcción del Puerto de La Luz y Las Palmas nace una relación contractual entre Juan de León y Castillo y la Swanston and Company. Fruto de esta relación es la elaboración de diversos informes que realiza el ingeniero con la finalidad de mostrar los graves perjuicios económicos que le estaban causando las prácticas contables seguidas por la empresa contratista. En estos informes profundiza en las técnicas contables aplicadas por la Swanston and Company y manifiesta de forma expresa y con diversos ejemplos los daños que le han causado, sirviéndonos todo ello para poner de manifiesto los conocimientos contables del ingeniero.

Los informes, cartas y demás documentación, junto con las transcripciones que realiza Juan de León y Castillo de la contabilidad de las obras de construcción del Puerto de La Luz y Las Palmas, forman parte del interesante fondo denominado Ingeniero D. Juan de León y Castillo.

Además, podemos afirmar que el origen de la mayor parte de dichos daños económicos se encontraban en la adición al contrato, al haberse establecido implícitamente una relación de canje fija entre la peseta y la libra esterlina. De esta forma, cualquier variación al alza de la moneda inglesa, lo usual de la época, afectaba de forma negativa al resultado contable de las obras y por tanto, a los intereses económicos de Juan de León y Castillo al cobrar en función de dicho resultado.

Por otra parte, hemos de resaltar la importancia de la Cuenta corriente de las obras con los Sres. Swanston y Cia. de Londres puesto que de su saldo dependía el reparto anual de las utilidades -beneficios-. Ahora bien, al haberse incluido en la cuenta anotaciones que reflejan actividades realizadas por la empresa contratista y ajenas a la construcción del puerto, su saldo ya no es el fiel reflejo del resultado a repartir.

Asimismo, Juan de León y Castillo cuando tuvo la oportunidad de examinar los datos contables, intentó comprobar la veracidad de los mismos y expuso el cálculo de las utilidades anuales y acumuladas para conocer la cuantía que de las mismas le correspondería, demostrando una vez más los saldos a su favor que la empresa constructora le debía.

Todo ello pone de manifiesto la relevancia de la contabilidad y sus prácticas, soporte de las operaciones contables y justificación de los hechos y actividades empresariales, que le permitieron al ingeniero, por una parte demostrar las inexactitudes cometidas por la Swanston and Company en el registro de las operaciones y cómo las mismas le perjudicaron al afectar a la cuantía que en concepto de remuneración debía percibir. Y por otra parte, dejar constancia en el tiempo del trabajo que Juan de León y Castillo realizó sin ser un experto en la

DE COMPUTIS Revista Española de Historia de la Contabilidad Spanish Journal of Accounting History 
administración económica empresarial y en su contabilidad, como hemos dado a conocer en este trabajo.

\section{BIBLIOGRAFÍA CITADA}

Burriel De Orueta, E.L. (1974): El puerto de La Luz en Las Palmas de Gran Canaria, Boletín 18, Centro de Investigación Económica y Social de la Caja Insular de Ahorros de Gran Canaria, Las Palmas de Gran Canaria.

Calvo Cruz, M.; Castro Pérez, C. y Granado Suárez, S. (2009): “La implicación de Juan de León y Castillo en la revisión de la contabilidad de la Swanston y Cia., constructora del puerto de La Luz", IV Congreso Internacional de Patrimonio e Historia de la Ingeniería (CIPHI), Las Palmas de Gran Canaria, 339350.

Calvo Cruz, M. y Castro Pérez, C. (2010): "Análisis de las discrepancias económicas entre Swanston y Cia., constructora del Puerto de La Luz (Canarias), y su ingeniero Juan de león y Castillo", Pecunia, 9, 4362.

Hernández Gutiérrez, A.S. (1991): El puerto de La Luz en la obra de Juan de León y Castillo, Escuela Universitaria Politécnica, Las Palmas de Gran Canaria.

(1995): Juan de León y Castillo: ingeniero, científico y humanista, Gobierno de Canarias, Las Palmas de Gran Canaria.

(2006): Biografías de Científicos Canarios. Juan de León y Castillo, Oficina de Ciencia, Tecnología e Innovación del Gobierno de Canarias, Las Palmas de Gran Canaria.

Herrera Piqué, A. (1977): "La colonia inglesa en Gran Canaria, una gran aventura", Aguayro, 94, 6-9.

Martín Hernández, U. (1995): "Presencia y actividades extranjeras en Canarias entre 1880 y 1919". Homenaje a Antonio Bethencourt Massieu, tomo II, 393-418, Las Palmas de gran Canaria: Cabildo Insular de Gran Canaria.

Martín Del Castillo, J.F. (1993): Ciencia y Política en el pensamiento de Juan de León y Castill, Cabildo Insular de Gran Canaria, Las Palmas de Gran Canaria.

(1995): “Ingeniería en Canarias, 1850-1900: Juan de León y Castillo", Boletín Millares Carlo, 14.

(1997): "Un aparato de gasolina diseñado por Juan de León y Castillo para el alumbrado de Las Palmas de Gran Canaria". Homenaje a Celso Martín de Guzmán, Universidad de Las Palmas de Gran Canaria.

(2003a): "El ingeniero Juan de León y Castillo y los ferrocarriles de Barcelona (1886-1890)", Transportes, Servicios y Telecomunicaciones, 6, 167-180.

(2003b): "Juan de León y Castillo: planos para una historia iconográfica de la ingeniería canaria: aproximación al diseño técnico del siglo pasado”, El Museo Canario, 58, 229-264.

Millares Torres, A (1982): Biografías de Canarios célebres. Edirca, Las Palmas de Gran Canaria.

Moralez Lezcano, V. (1971): "Inversiones inglesas en Canarias durante el siglo XIX", Moneda y Crédito 118, 101-121.

Moreno, J.C. (1947): De los puertos de la Luz y Las Palmas y otras historias. Gabinete Literario, Las Palmas de Gran Canaria.

Quintana Navarro, F. (1985b): Pequeña Historia del Puerto de Refugio de La Luz. Colección Guagua, Las Palmas de Gran Canaria.

Revista de Obras Públicas (1882), 4, tomo XXX.

Rodríguez Díaz De Quintana, M. (1989): Miller y compañía: cien años de historia. Miller y Compañía, Las Palmas de Gran Canaria.

DE COMPUTIS Revista Española de Historia de la Contabilidad Spanish Journal of Accounting History 
Suárez Falcón, J. (1952): El puerto de La Luz y los hermanos León y Castillo. Tipografía Alzota, Las Palmas de Gran Canaria.

Tipografía del Diario (1909): El puerto de La Luz en Gran Canaria. Las Palmas de Gran Canaria.

Mercedes Calvo Cruz es Profesora Titular de Universidad en el Departamento de Economía Financiera y Contabilidad de la Universidad de Las Palmas de Gran Canaria, España. Su e-mail es: mcalvo@ defc.ulpgc.es.

Candelaria Castro Pérez es Profesora Titular de Escuela Universitaria en el Departamento Economía Financiera y Contabilidad de la Universidad de Las Palmas de Gran Canaria, España. Su e-mail es: ccastro@defc.ulpgc.es.

Mercedes Calvo Cruz is Associate Professor of Accounting and Finance at the University de Las Palmas de Gran Canaria, Spain. Her e-mail is: mcalvo@ defc.ulpgc.es.

Candelaria Castro Rerez is Associate Professor of Accounting and Finance at the Business School of the University de Las Palmas de Gran Canaria, Spain. Her e-mail is: ccastro@ defc.ulpgc.es. 


\section{Anexo 1. Contrato firmado entre la Swanston and Company y Juan de León y Castillo}

Habiendo el señor D. Juan de León y Castillo cesado en el destino de Ingeniero Jefe de la Provincia de Canarias y estando con licencia del Gobierno y pudiendo por lo mismo encargarse de obras particulares, y los Sres. Swanston y Cia., contratistas de las obras del Puerto Refugio de La Luz, deseando aprovechar la inteligencia como Ingeniero e influencias como hombre político del dicho Sr. D. Juan de León y Castillo han convenido el contrato siguiente:

$1^{\circ}$. Nombrar desde el 19 de julio del corriente al Sr. D. Juan de León y Castillo Ingeniero Director y Consultivo en las Obras del Puerto de Refugio para dirigir los trabajos en todo o concerniente a dicho ramo, levantar los planos necesarios, etc., en los términos y con las condiciones del contrato con el Gobierno.

$2^{\circ}$. Dicho Sr. D. Juan de León y Castillo se obliga a emplear todo el influjo que posee y el de sus amigos tanto en Canarias como en Madrid para el mejor y más rápido desarrollo de dichas obras en conseguir los Certificados mensuales en Canarias y el pago de las mismas a la mayor brevedad y allanar las dificultades que puedan presentarse.

$3^{\mathrm{o}}$. En remuneración de los servicios estipulados en las condiciones $1^{\mathrm{a}}$ y $2^{\mathrm{a}}$, los Sres. Swanston y Cia. darán al Sr. León y Castillo en efectivo una suma equivalente a la tercera parte de las utilidades netas que se obtengan de las dichas Obras del Puerto Refugio desde $1^{\circ}$ de julio hasta su terminación.

$4^{\circ}$. No siendo posible verificar en el día una liquidación exacta conviene las dos partes contratantes en fijar las utilidades obtenidas hasta la fecha en $£ 18.000$ (diez y ocho mil libras esterlinas) por lo cual el Sr. León y Castillo sólo tiene derecho a la tercera parte de las utilidades que arroje la liquidación final o la que bajo la cláusula $8^{\mathrm{a}}$ ha de levantarse en caso de su muerte, deduciendo de ella las mencionadas $£ 18.000$.

$5^{\circ}$. Todos los gastos que se hayan incurrido y puedan aún incurrirse hasta la terminación de las obras o hasta la terminación de este contrato según cláusula $8^{\mathrm{a}}$, en consultas, trabajos de otros Ingenieros, etc., así como ciertos gastos de índole reservada referente a la inspección de las obras y para el debido cumplimiento de las condiciones $1^{\mathrm{a}}$ y $2^{\mathrm{a}}$ serán de la exclusiva cuenta del Sr. León y Castillo y se deducirán de la tercera parte de utilidades que le correspondan por condiciones $3^{\mathrm{a}}$ y $4^{\mathrm{a}}$.

$6^{\circ}$. Como no puede averiguarse con exactitud los beneficios resultantes hasta la terminación final de las obras, y su entrega al Gobierno, se ha convenido en repartir en las proporciones indicadas el balance que haya hasta el día 30 de junio de cada año a favor de las dichas obras en la cuenta corriente que llevan los Sres. Swanston y Cia. con las mismas en Londres.

Si el dicho balance fuese más de $£ 3.000$ (tres mil libras esterlinas) sólo se repartirán $£ 3.000$, quedando el sobrante para formar una cuenta de Reserva para hacer frente a cualquiera eventualidad contraria.

\section{DE COMPUTIS Revista Española de Historia de la Contabilidad} Spanish Journal of Accounting History 
$7^{\circ}$. En caso de ausencia permanente o incapacidad del Sr. León u Castillo imposibilitándole cumplir las condiciones $1^{\mathrm{a}}$ y $2^{\mathrm{a}}$ de este contrato los Sres. Swanston y Cia. tendrán el derecho de nombrar un sustituto por cuenta y a costos del Sr. León y Castillo.

$8^{a}$. Este contrato es absolutamente personal, y por tanto libre de toda intervención de terceras partes y en el caso de la muerte del Sr. León y Castillo cesa en el acto, y sus herederos solamente tendrán derecho a percibir la parte correspondiente de utilidades habidas y pendientes de pago en aquel día según liquidación que harán los Sres. Swanston y Cia. tan pronto como les sea posible y con la cual se han de conformar los interesados.

$9^{\circ}$. Aunque al Sr. León y Castillo se le remunera con una proporción de las utilidades no por eso se constituye Sociedad Mercantil de ninguna clase entre las partes contratantes, ni se le dá a dicho Sr. Intervención en la Contabilidad y Administración de las dichas obras, las que quedan como hasta hoy a cargo y dirección exclusiva de los Contratistas y de sus representantes.

$10^{\circ}$. Al Sr. D. Juan de León y Castillo se le enterará de la marcha que llevan las obras pero no tendrá derecho a exigir cuentas de ninguna clase y además se obliga desde luego a conformarse con las cuentas y liquidaciones que levanten los Sres. Swanston y Cia., los contratistas.

$\mathrm{Y}$ en prueba de su conformidad firman ambas partes este convenio por duplicado, Londres y julio veinte y cuatro de mil ochocientos noventa y uno.

Swanston y $\mathrm{C}$

Las Palmas 23 de octubre de 1891

Adición:

A ruego del Sor. Don Juan de León y Castillo se ha convenido en anticiparle anualmente la suma de quince mil pesetas (15.000) o sean seiscientas libras ( $£ 600)$ a cuenta de las $£ 1.000$ que le corresponde según la cláusula $6^{a}$. Estos adelantos se harán en Las Palmas en sumas iguales de tres mil setecientas cincuenta pesetas (3.750) cada trimestre y el Sor. León y Castillo abonará un interés del $6 \%$ anual desde la fecha de la entrega hasta el de reembolso.

Las Palmas 23 de octubre de 1891

Swanston y C

Juan de León y Castillo

DE COMPUTIS Revista Española de Historia de la Contabilidad Spanish Journal of Accounting History 
Candelaria Castro Pérez y Mercedes Calvo Cruz: Análisis descriptivo de la contabilidad de las obras del Puerto de La Luz y Las Palmas (Canarias,España) a través del estudio realizado por su director el ingeniero Juan de León y Castillo, siglos XIX y XX

Anexo 2. Figura 1: Cuenta corriente de las obras con los sres. Swanston y Cia. de Londres, 1 de enero de 1892 a 30 de junio de 1892

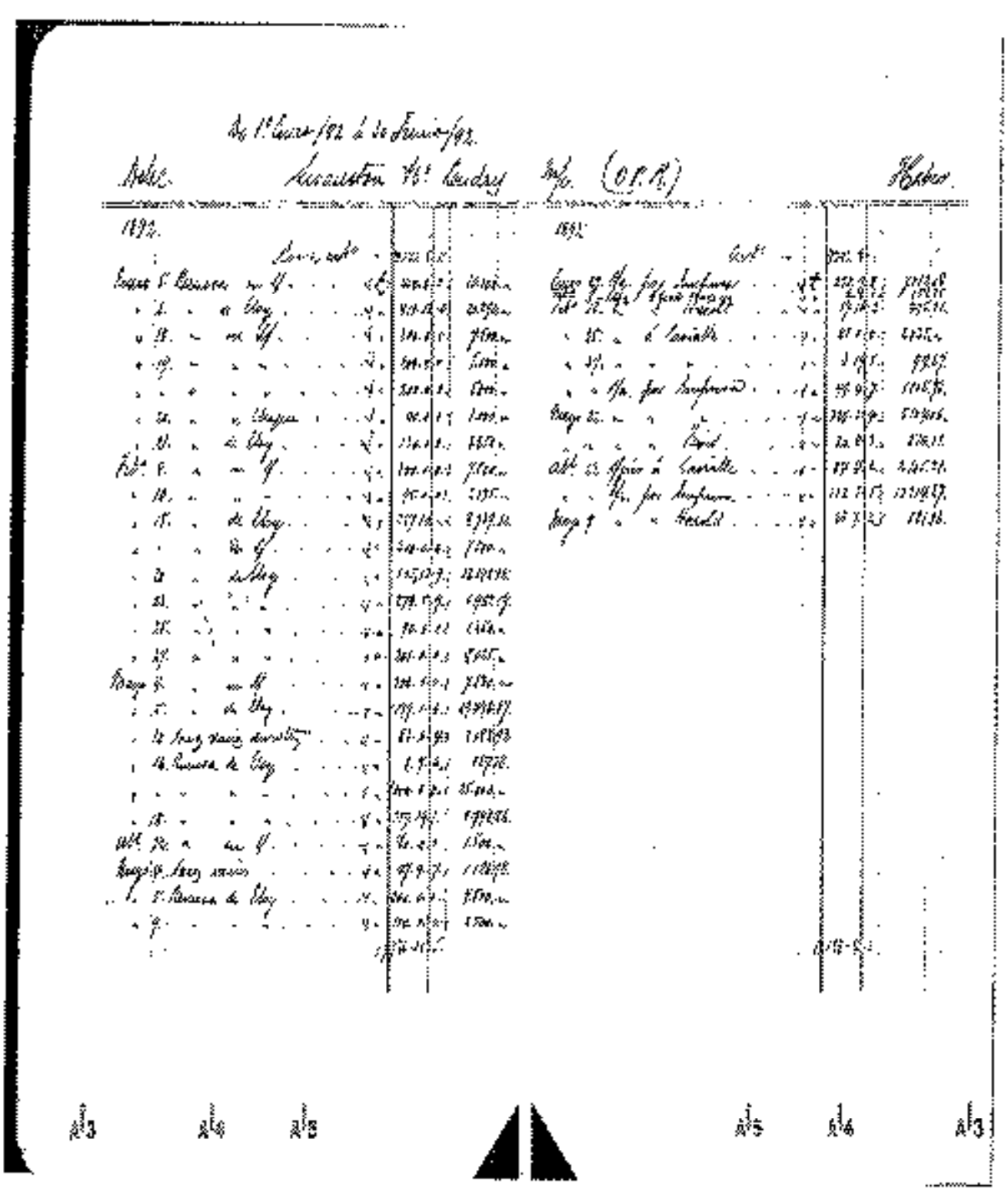

DE COMPUTIS Revista Española de Historia de la Contabilidad Spanish Journal of Accounting History

No. 13

Diciembre 2010 
Candelaria Castro Pérez y Mercedes Calvo Cruz: Análisis descriptivo de la contabilidad de las obras del Puerto de La Luz y Las Palmas (Canarias,España) a través del estudio realizado por su director el ingeniero Juan de León y Castillo, siglos XIX y XX

Anexo 3. Figura 2: Cuenta corriente de Swanston y Cia. de Las Palmas, 1895

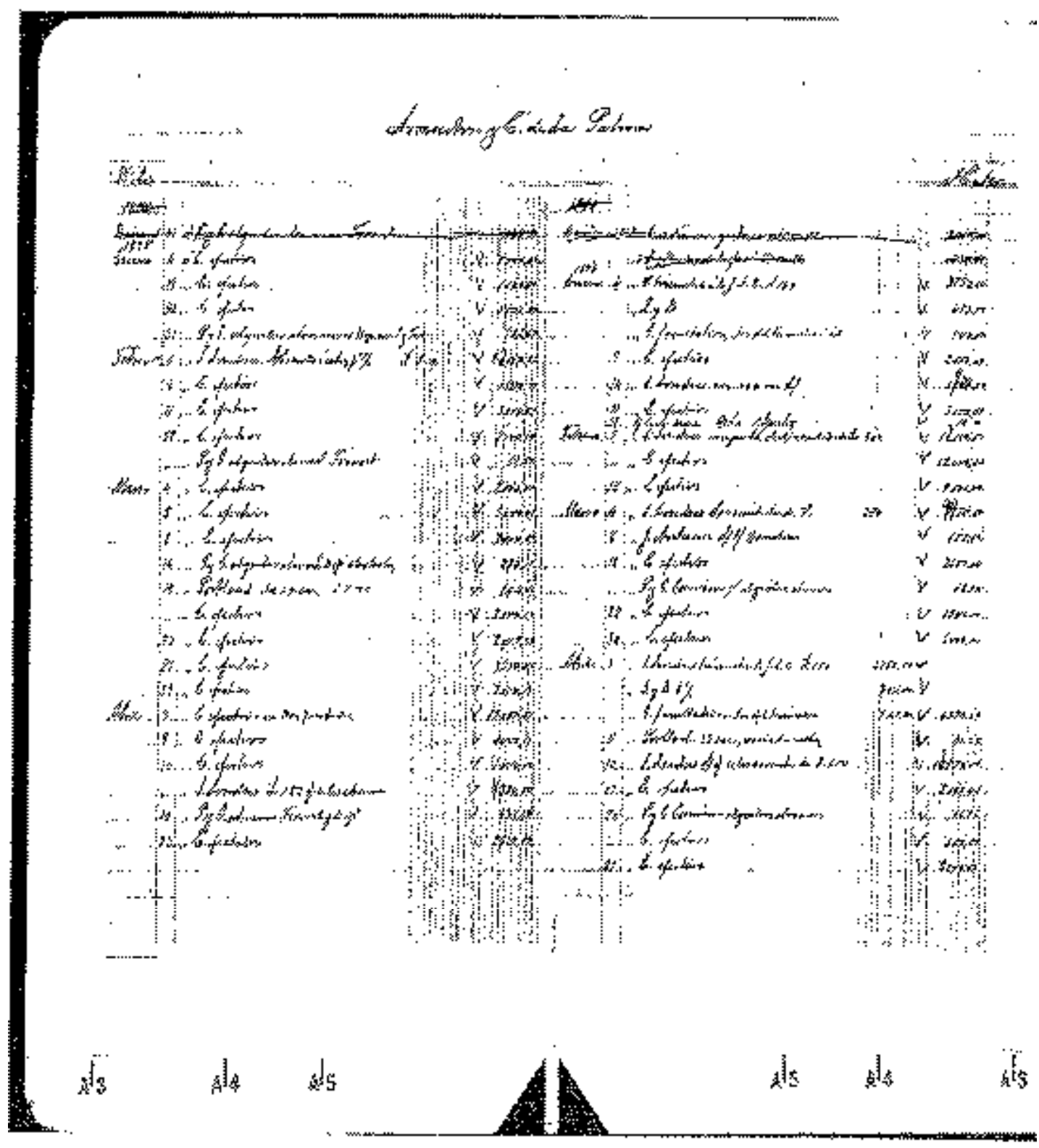

DE COMPUTIS Revista Española de Historia de la Contabilidad Spanish Journal of Accounting History

No. 13

Diciembre 2010 
Candelaria Castro Pérez y Mercedes Calvo Cruz: Análisis descriptivo de la contabilidad de las obras del Puerto de La Luz y Las Palmas (Canarias,España) a través del estudio realizado por su director el ingeniero Juan de León y Castillo, siglos XIX y XX

Anexo 4. Figura 3: Cuenta del depósito de carbón adosado al dique de abrigo, 1891

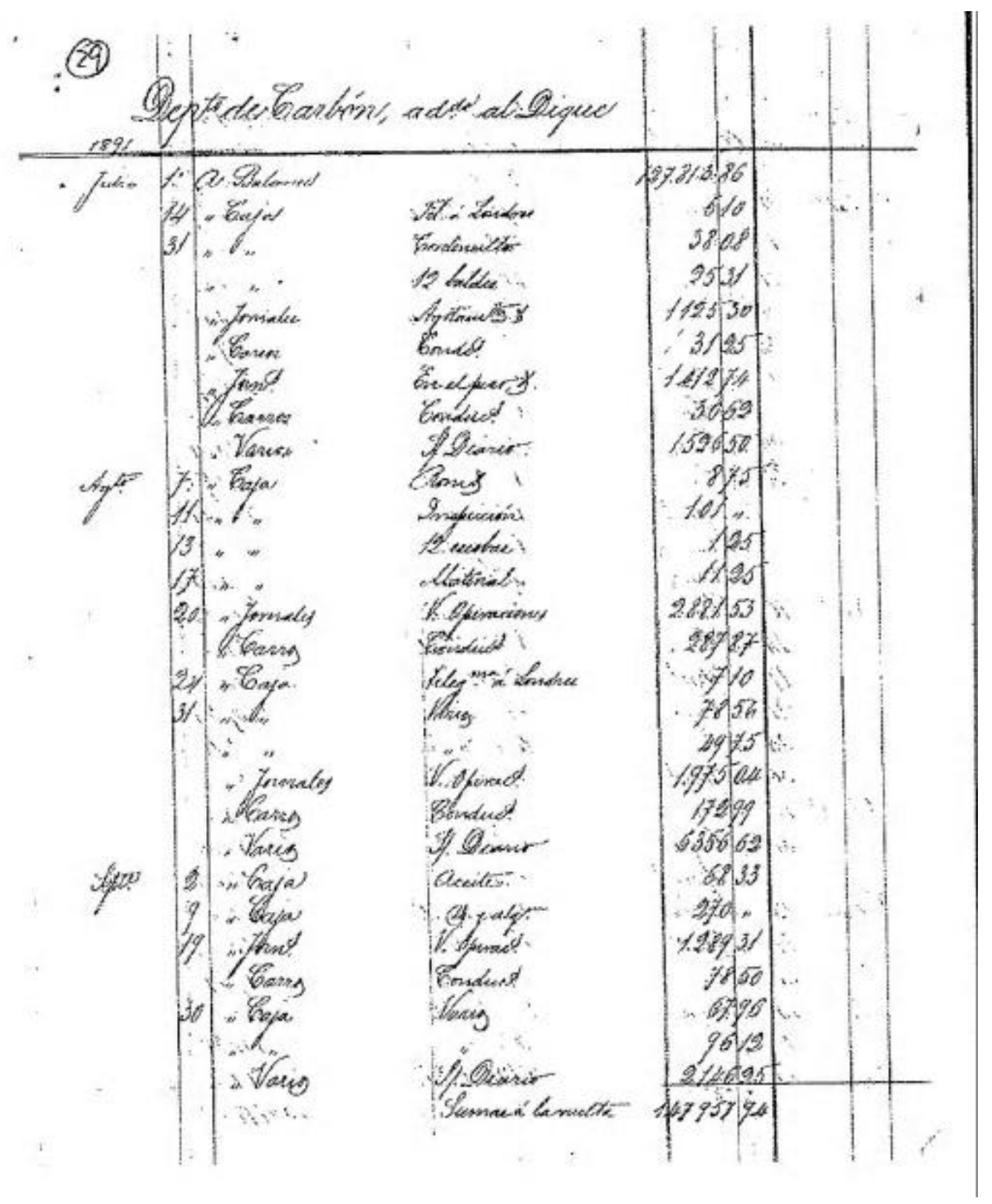

\footnotetext{
DE COMPUTIS Revista Española de Historia de la Contabilidad Spanish Journal of Accounting History
} 
Candelaria Castro Pérez y Mercedes Calvo Cruz: Análisis descriptivo de la contabilidad de las obras del Puerto de La Luz y Las Palmas (Canarias,España) a través del estudio realizado por su director el ingeniero Juan de León y Castillo, siglos XIX y XX

Anexo 5. Figura 4: Balance de cuentas de las obras del Puerto Refugio, 1899

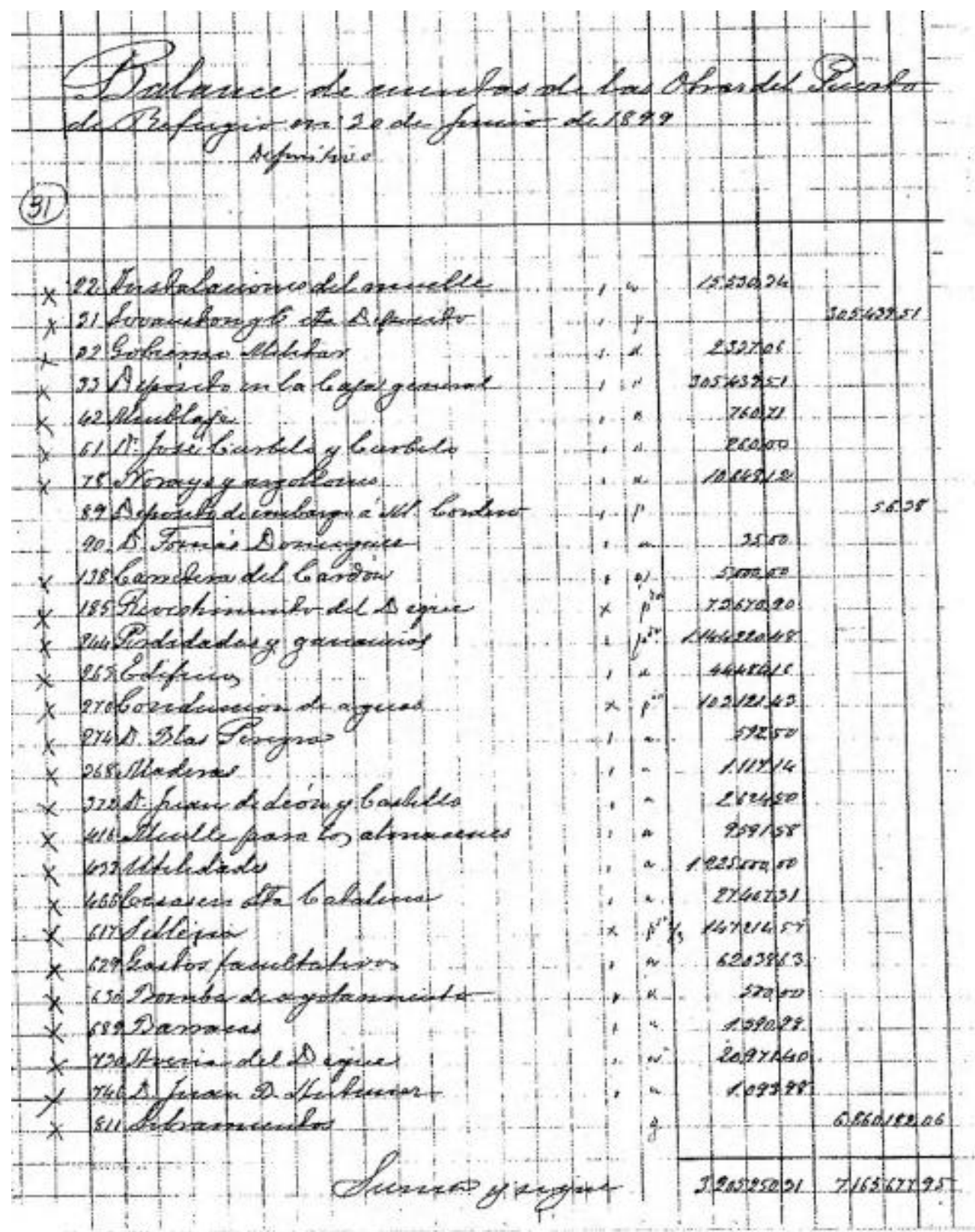

DE COMPUTIS Revista Española de Historia de la Contabilidad Spanish Journal of Accounting History 
Candelaria Castro Pérez y Mercedes Calvo Cruz: Análisis descriptivo de la contabilidad de las obras del Puerto de La Luz y Las Palmas (Canarias,España) a través del estudio realizado por su director el ingeniero Juan de León y Castillo, siglos XIX y XX

\section{Anexo 5 (continuación). Figura 5}

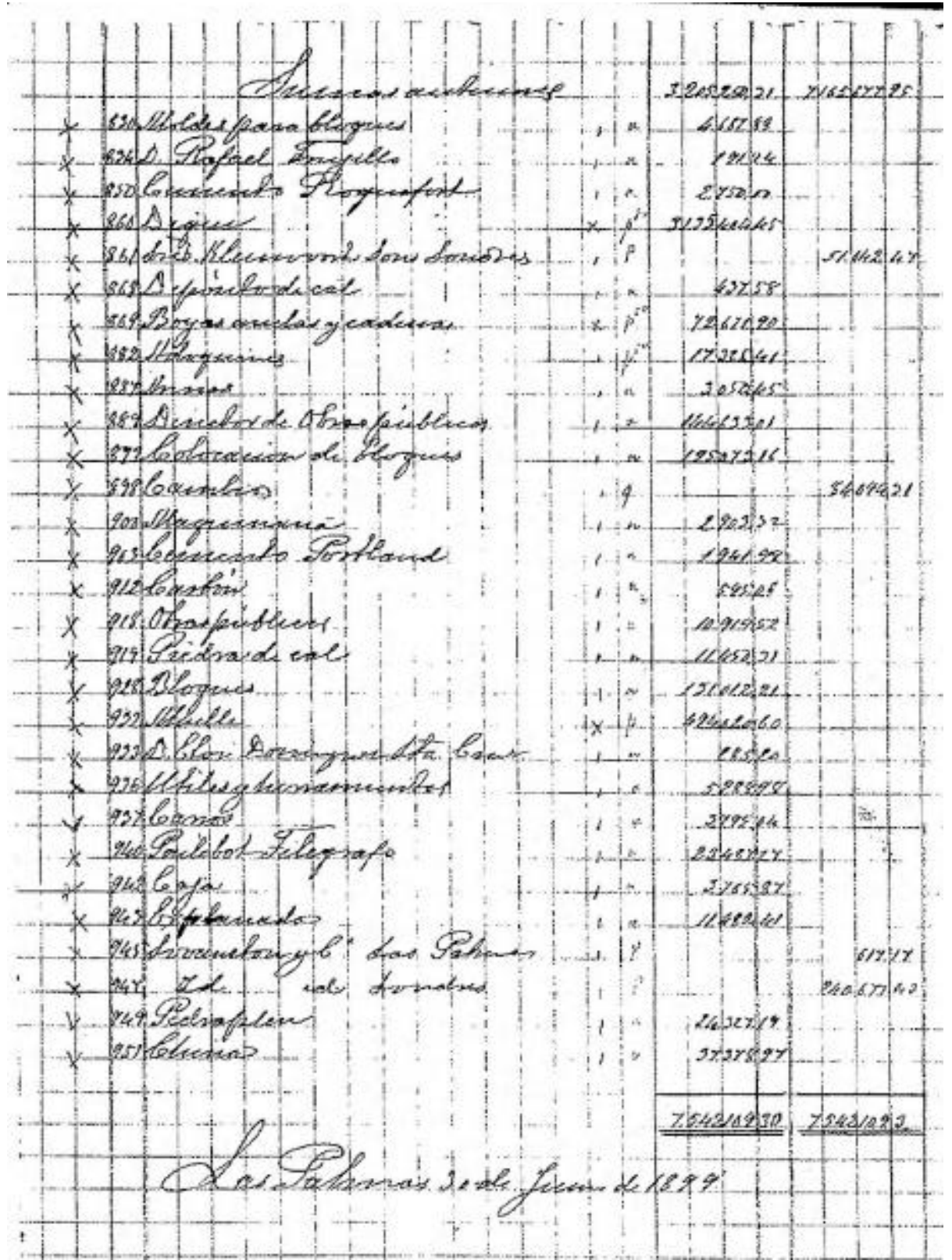

DE COMPUTIS Revista Española de Historia de la Contabilidad Spanish Journal of Accounting History 
Candelaria Castro Pérez y Mercedes Calvo Cruz: Análisis descriptivo de la contabilidad de las obras del Puerto de La Luz y Las Palmas (Canarias,España) a través del estudio realizado por su director el ingeniero Juan de León y Castillo, siglos XIX y XX

Anexo 6. Figura 6: Determinación de las utilidades acumuladas hasta el 30 de junio de 1894

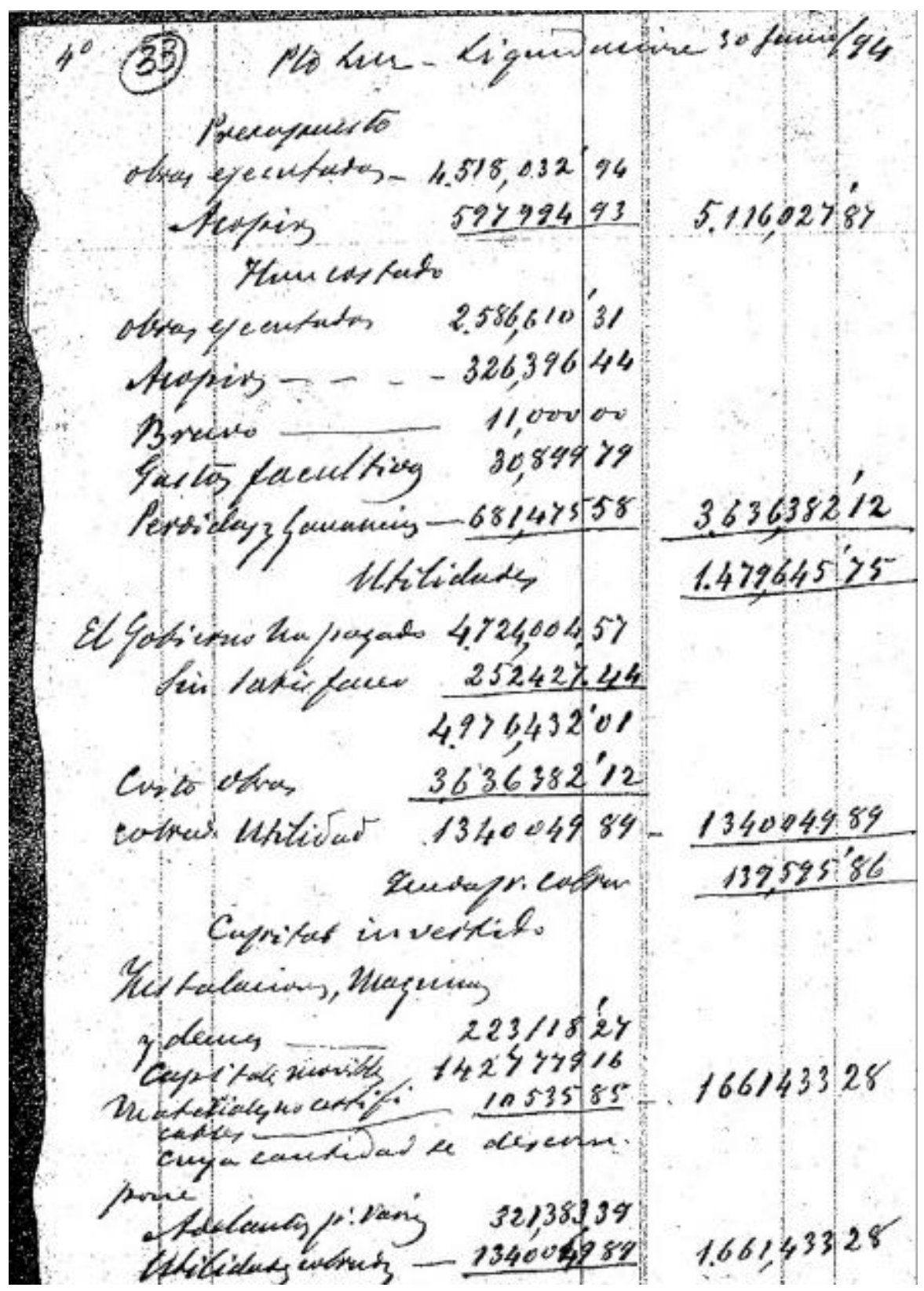

DE COMPUTIS Revista Española de Historia de la Contabilidad Spanish Journal of Accounting History 
Candelaria Castro Pérez y Mercedes Calvo Cruz: Análisis descriptivo de la contabilidad de las obras del Puerto de La Luz y Las Palmas (Canarias,España) a través del estudio realizado por su director el ingeniero Juan de León y Castillo, siglos XIX y XX

Anexo 7. Figura 7: Determinación de las utilidades, ratio de rentabilidad y deuda de la Swanston con Juan De León y Castillo, 30 de junio de 1893 a 30 de junio de 1894

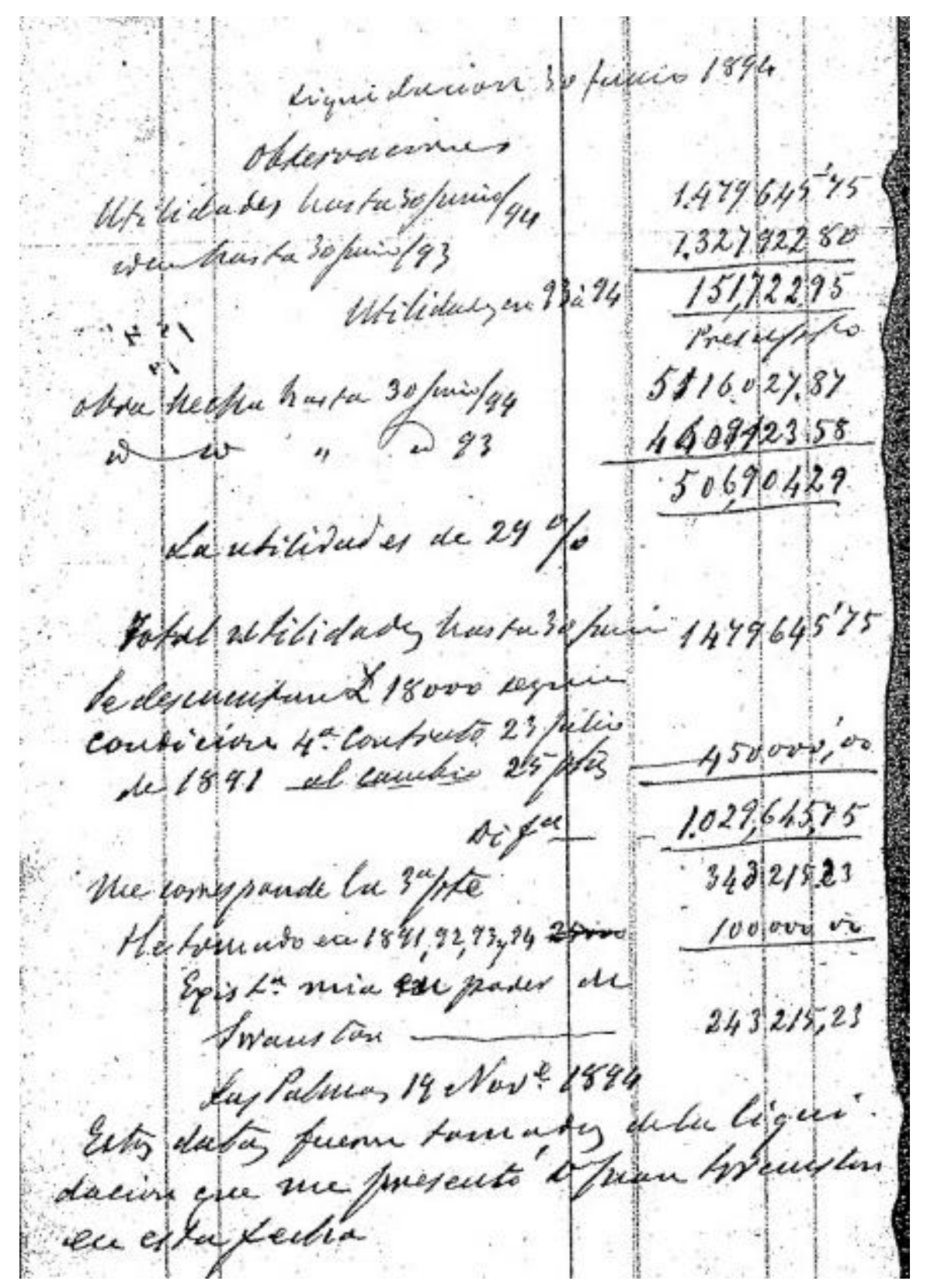

DE COMPUTIS Revista Española de Historia de la Contabilidad Spanish Journal of Accounting History 